\title{
COVID-19 lockdown only partially alleviates health impacts of air pollution in Northern Italy
}

To cite this article before publication: Francesco Granella et al 2020 Environ. Res. Lett. in press https://doi.org/10.1088/1748-9326/abd3d2

\section{Manuscript version: Accepted Manuscript}

Accepted Manuscript is "the version of the article accepted for publication including all changes made as a result of the peer review process, and which may also include the addition to the article by IOP Publishing of a header, an article ID, a cover sheet and/or an 'Accepted

Manuscript' watermark, but excluding any other editing, typesetting or other changes made by IOP Publishing and/or its licensors"

This Accepted Manuscript is @ $\mathbf{2 0 2 0}$ The Author(s). Published by IOP Publishing Ltd.

As the Version of Record of this article is going to be / has been published on a gold open access basis under a CC BY 3.0 licence, this Accepted Manuscript is available for reuse under a CC BY 3.0 licence immediately.

Everyone is permitted to use all or part of the original content in this article, provided that they adhere to all the terms of the licence https://creativecommons.org/licences/by/3.0

Although reasonable endeavours have been taken to obtain all necessary permissions from third parties to include their copyrighted content within this article, their full citation and copyright line may not be present in this Accepted Manuscript version. Before using any content from this article, please refer to the Version of Record on IOPscience once published for full citation and copyright details, as permissions may be required. All third party content is fully copyright protected and is not published on a gold open access basis under a CC BY licence, unless that is specifically stated in the figure caption in the Version of Record.

View the article online for updates and enhancements. 


\section{COVID-19 lockdown only partially alleviates health impacts} of air pollution in Northern Italy

Francesco Granella*a,b, Lara Aleluia Reis ${ }^{\mathrm{b}}$, Valentina Bosetti ${ }^{\mathrm{a}, \mathrm{b}}$ and Massimo Tavoni ${ }^{b, c}$

${ }^{a}$ Bocconi University

${ }^{\mathrm{b}} \mathrm{RFF}-\mathrm{CMCC}$ European Institute on Economics and the Environment ${ }^{c}$ Politecnico di Milano

Evaluating the reduction in pollution caused by a sudden change in emission is complicated by the confounding effect of weather variations. We propose an approach based on machine learning to build counterfactual scenarios that address the effect of weather and apply it to the COVID-19 lockdown of Lombardy, Italy. We show that the lockdown reduced background concentrations of $\mathrm{PM}_{2.5}$ by $3.84 \mu \mathrm{g} / \mathrm{m}^{3}(16 \%)$ and $\mathrm{NO}_{2}$ by $10.85 \mu \mathrm{g} / \mathrm{m}^{3}(33 \%)$. Improvement in air quality saved at least $11 \%$ of the years of life lost and $19 \%$ of the premature deaths attributable to COVID-19 in the region during the same period. The analysis highlights the benefits of improving air quality and the need for an integrated policy response addressing the full diversity of emission sources.

Keywords: Air pollution, COVID-19, machine learning, health

*Corresponding author, francesco.granella@unibocconi.it.

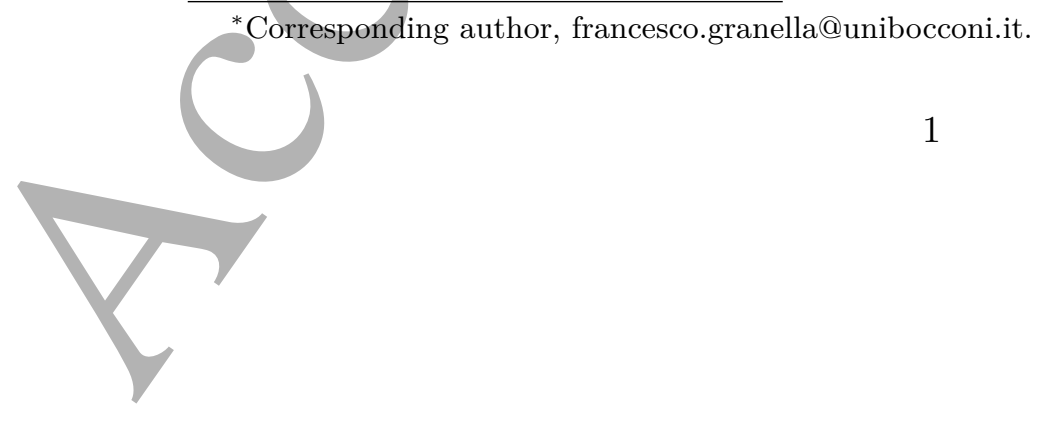




\section{Introduction}

Exposure to airborne pollutants is detrimental to human health. Fine particulate matter $\left(\mathrm{PM}_{2.5}\right)$ increases mortality rates and hospitalizations due to respiratory and cardiovascular disease (Pope and Dockery 2006; Ebenstein et al. 2017; Deryugina et al. 2019). Additionally, it leads to a decline in physical and cognitive productivity (Graff Zivin and Neidell 2012; Ebenstein et al. 2016; Zhang et al. 2018; He et al. 2019; Kahn and Li 2020). Similarly, exposure to nitrogen dioxide $\left(\mathrm{NO}_{2}\right)$ leads to an increase in hospital admissions and premature mortality (Mills et al. 2015; Amini et al. 2019; Duan et al. 2019).

The design of effective pollution abatement policies requires a comprehensive understanding of the relationship between reductions of emissions and concentrations. However, the processes of formation, transport, and dispersion of pollutants are complex phenomena, introducing considerable uncertainty on the effect of policies on air quality. Moreover, impact assessments need to address the confounding effect of annual and daily weather variations, a significant driver of pollutant concentrations.

This paper provides novel evidence on the change in concentrations of PM 2.5 following a composite reduction in emissions across different sources. Specifically, we exploit the dramatic decrease in Italy's mobility and economic activity in response to the COVID-19 outbreak from late February to early May. We provide causal estimates of the change in $\mathrm{PM}_{2.5}$ and $\mathrm{NO}_{2}$ over more than two months for Lombardy, one of the most polluted regions among Organisation for Economic Co-operation and Development countries, and one of the first areas outside China that imposed a strict lockdown.

Using a machine-learning algorithm, we address the confounding effect of weather and build a counterfactual scenario of the pollution concentrations that would have occurred if the COVID-19 pandemic had not broken out and no lockdown had been implemented. Finally, we compute the years of life saved and the number of premature deaths avoided 
by the improvement in air quality. We compare these numbers against the years of life lost and premature deaths due to COVID-19 in the region over the same period.

Ex-post studies can provide valuable estimates of the sensitivity of concentrations to emissions. However, a host of confounding factors can seriously hinder policy evaluation. In particular, the concentration of airborne pollutants is highly dependent on atmospheric conditions. Formation, transport, dispersion, and even emission of pollutants are directly or indirectly affected by the weather (Kroll et al. 2020). For instance, severe haze events in Beijing follow periodic cycles governed by meteorological conditions, especially wind patterns (Guo et al. 2014). Unless the confounding impact of weather is accounted for, the estimated change in concentrations following intervention will be biased.

A common approach to impact evaluation of pollution/control policies is comparing areas that were affected by a policy and (areas that were not (e.g., He et al. (2020) and Cole et al. (2020) for the case of COVID-19 lockdowns). However, even when differences in weather have been accounted for, unaffected and comparable areas may not always exist. For the problem at hand, a precise separation between affected and unaffected regions is not possible, considering the ubiquitous adoption of measures to control the spreading of COVID-19.

We turn the complex correlation of weather and pollution to our favor, predicting concentrations as a function of weather variables and season with machine learning. We follow a simple strategy, similar to Petetin et al. (2020), that does not require the availability of comparable but unaffected regions. For each air pollution monitoring station in Lombardy, we train an extreme gradient boosting regressor (Friedman 2001), a treebased machine learning algorithm, over daily concentrations from 2012 to 2019 and predict concentrations for the first four months of 2020. We show in Supplementary information that this approach is more reliable than linear regression models. To account for any con- 
stant error in our prediction, including inter-annual trends (Silver et al. 2020), we adopt a difference-in-differences strategy. We identify the average impact of the lockdown on air pollution concentrations as the difference between the prediction error before and during the lockdown.

We find that, despite the unprecedented halt in mobility and economic activity, the concentrations of major pollutants only partially decreased as a consequence of the lockdown. Background concentrations of $\mathrm{PM}_{2.5}$ and $\mathrm{NO}_{2}$ decreased by $3.84 \mu \mathrm{g} / \mathrm{m}^{3}$ (16\%) and 10.85 $\mu \mathrm{g} / \mathrm{m}^{3}(33 \%)$, respectively. Nonetheless, the improvement in air quality saved at least $11 \%$ of the years of life lost and $19 \%$ of the premature deaths attributable to COVID-19 in the region during the same period.

This paper contributes to several active strands of literature in air pollution research. First, it speaks to works on the assessment of pollution control policies, and in particular, to the growing corpus of research employing machine learning and fine-grained data. The paper illustrates an innovative procedure to quantify the implications of a change in emissions on outdoor concentrations of pollutants, isolating the effect of weather variability. While existing studies applying a similar approach restrict the analysis to no more than a few days, we show the conditions under which the procedure can be applied to longer time windows, the length of weeks or months. We illustrate the approach through a specific event - the lockdown of Lombardy, in Northern Italy - but it can be generalized wherever spatially and temporally detailed data on air pollution concentrations and atmospheric conditions are available.

Second, this paper is relevant to pollution control policies in the domain of study. Lombardy is a high-income, densely populated region, home to approximately 10 million people, and one of the most polluted in OECD countries. The European Commission has repeatedly referred Italy to the Court of Justice of the European Union over persistently 
high levels of $\mathrm{NO}_{2}$ and $\mathrm{PM}_{10}$, mainly in Lombardy and the rest of the Po Valley (European Commission v. Italian Republic 2012, 2019, 2020). This study sheds light on the sectoral contributions to emissions of $\mathrm{PM}_{2.5}$ and $\mathrm{NO}_{2}$, offering tools to regulators and policymakers.

Finally, our study relates to the literature on source apportionment to different sectors, particularly agriculture, a topic of increasing relevance (Lelieveld et al. 2015). During the study period, agricultural production continued unaffected, and on average $11.6 \mathrm{\mu g} / \mathrm{m}^{3}$ $(39 \%)$ of $\mathrm{PM}_{10}$ in Milan, the largest city, were attributable to agriculture. We acknowledge that missing sufficient data on 2020 sectoral emissions and on the composition of $\mathrm{PM}_{2.5}$, source apportionment to different sectors remains elusive. Were the data available, our machine learning approach could be used to exactly estimate changes in the composition of $\mathrm{PM}_{2.5}$.

\section{Sectoral emissions during lockdown}

The timing and nature of the lockdown of Lombardy and Italy are discussed in detail in the Supplementary information. We highlight here two key moments. On February 21, 2020, the first outbreak of COVID-19 in Italy was identified in the south of Lombardy. Within 24 hours, 11 municipalities in the region went under strict lockdown: schools were closed, all non-essential economic activities had to stop, and a stay-at-home order was in place. Teaching activities in the rest of Lombardy also were suspended. On March 8, authorities extended the lockdown to the rest of Lombardy; and to the rest of Italy on the following day. Lockdown measures were kept in place almost unaltered until May 4.

The progressive spreading of the virus in Northern Italy and the tightening of containment measures have substantially reduced mobility and economic activity. As mobile phone data reveals, the movement of individuals in Lombardy has followed a two-step response, following the first outbreak of COVID-19 cases in lower Lombardy (February 21) 
and the lockdown of the entire country (March 9) (Figure 1a). By mid-March, mobility dropped by three-fourths, according to data compiled by Google and Apple (Google 2020; Apple 2020). Under lockdown, all non-essential industrial production halted. As a consequence, energy demand in Northern Italy steadily decreased since March 9, as businesses shut down, bottoming to $50 \%$ of pre-lockdown levels after two weeks (Figure 1b).

However, not all major sources of emissions, especially those releasing precursors of $\mathrm{PM}_{2.5}$, have been affected by restrictions. The lockdown forced most people to home isolation; it is sensible to hypothesize that emissions from residential buildings increased as a consequence. On the other hand, emissions from non-residential buildings might have decreased. Although data to confirm this is lacking, it is plausible that emissions from heating systems have not been affected substantially.

During the transition between winter and spring, agriculture becomes an important source of secondary $\mathrm{PM}_{2.5}$ in Lombardy (INEMAR 2017). The dispersal of animal liquids on open fields is a common (though regulated) practice that releases ammonia in the atmosphere, a precursor to secondary $\mathrm{PM}_{2.5}$. Public authorities have not restricted agricultural activities during lockdown in the interest of securing food supplies. These practices have continued virtually unchanged compared to previous years (personal exchange with public officials at the regional office for agriculture).

The agricultural sector is responsible for almost all emissions of ammonia $\left(\mathrm{NH}_{3}\right)$ in the region (INEMAR 2017), a precursor to particulate matter as it combines into ammonium nitrates and ammonium sulfates. Data on the decomposition of background $\mathrm{PM}_{10}$ in Milan shows that ammonium nitrates and ammonium sulfates accounted for almost $40 \%$ of $\mathrm{PM}_{10}$ concentrations during the lockdown (see Figure A.4 in Supplementary information). This corroborates the evidence that restrictive measures did not meaningfully alter agricultural emissions. 
(a)

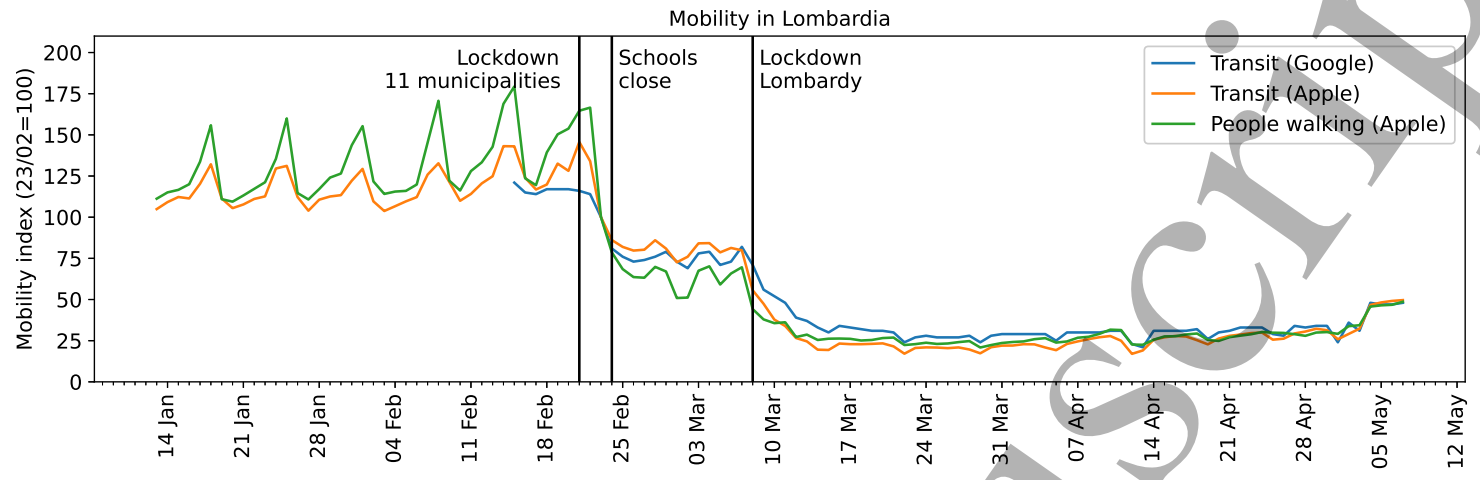

(b)

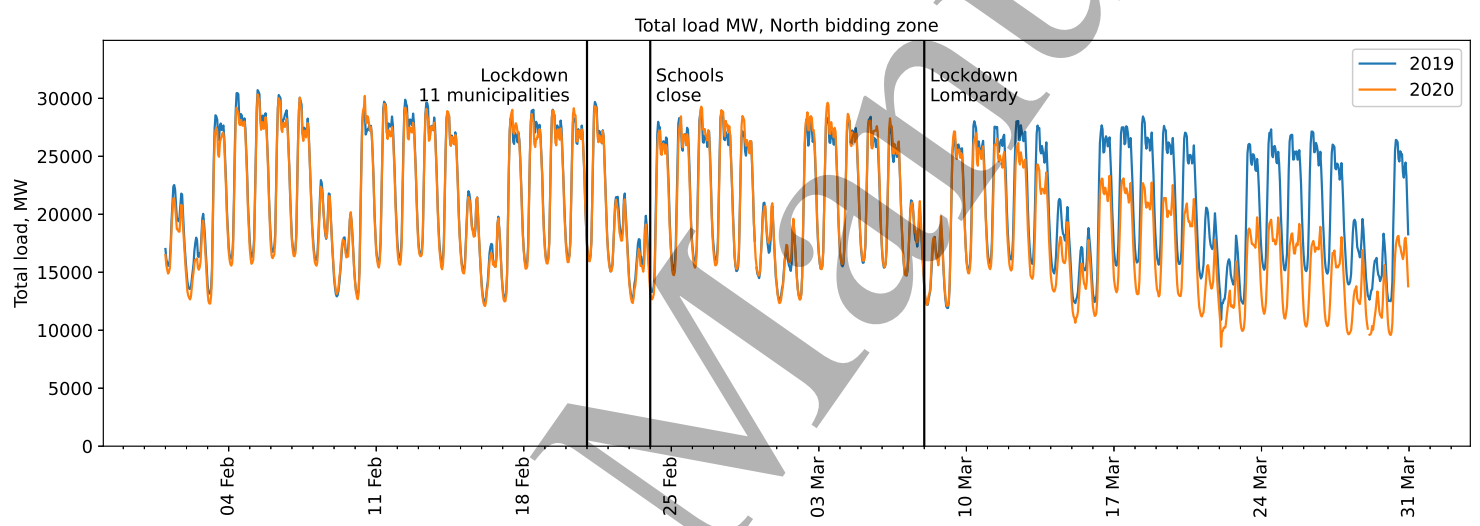

Figure 1: Proxies of sectoral emissions. a, Mobility indices for Milan Lombardy based on mobile phone data. Indices equal 100 on February 23. Source: Google (2020); Apple (2020). b, Total load of energy demand in Northern Italy in MW, 2019 vs 2010. The time series of 2019 has been shifted to match the day of the week. Source: TERNA (2020).

\section{Methods}

\subsection{Machine learning}

To identify the causal effect of the lockdown on concentrations without directly observing emissions, we build a synthetic counterfactual. We train a machine learning algorithm that can reproduce pollution concentrations on a business-as-usual scenario, and then predict 
concentrations during the lockdown. The difference between observed concentrations and the counterfactual, or prediction error, is the effect of the intervention. To account for potential systemic bias in the counterfactual, we adopt a difference-in-differences strategy. We identify the average impact of the lockdown on concentrations as the difference between the average prediction error before and during the lockdown. This approach does not require identifying comparable regions whose concentrations follow a business-as-usual trend.

We first assemble a dataset of air pollution, atmospheric conditions, and calendar variables for the period 2012 to 2020 for the Italian region of Lombardy. Pollution concentrations are measured at 83 monitoring stations. Data on daily minimum and maximum temperature, average wind speed and wind direction, average relative humidity, daily cumulative precipitation, and atmospheric soundings come from 227 weather stations.

For every monitoring station, we build the counterfactual using an extreme gradient boosting regressor, a tree-based model (Friedman 2001). ${ }^{1}$ Next, monitor by monitor, we train the algorithm on data from 2012 through 2019 and predict concentrations of $\mathrm{PM}_{2.5}$ and $\mathrm{NO}_{2}$ in 2020. We use the pre-lockdown period from January 1 to February 22, which was not included in the training set, to assess the validity of the counterfactual.

As our ultimate goal is a reliable prediction of pollutant concentrations from January through early May 2020, cross-validation is performed over four folds, each one consisting of the months from January to April for 2016, 2017, 2018, and 2019. The more common cross-validation on random subsamples, or folds, gives equal weight to all seasons. However, with such validation strategy it cannot be ruled out that an algorithm make good average predictions, while over-predicting in one season and under-predicting in the opposite one. Suppose, for instance, that the predictions of a learner are positively biased in spring, neg-

${ }^{1}$ We use the python package xgboost (Chen and Guestrin 2016). 
atively biased in fall, and unbiased in winter and summer. In this case, testing predictions on the pre-lockdown period (in wintertime) does not give correct estimates of the bias during the lockdown (in springtime). For this reason, we perform cross-validation over the months for which we want predictions to be reliable. Model parameters are selected to maximize the cross-validated RMSE.

The identification strategy relies on two assumptions. First, input variables should not be themselves affected by the intervention; otherwise, estimated effects will be biased towards zero. To this end, we exploit the sensitivity of concentrations to meteorological conditions and build the counterfactual as a function of weather and season. While emissions are affected by weather (e.g., lower emissions from heating systems on warmer days), our identification assumption is not violated as the weather is not affected by emissions. On the other hand, the algorithm implicitly learns the patterns of emissions as the weather varies and seasons pass.

Second, emissions that would have materialized absent the lockdown, and once weather has been accounted for, should be equal to emissions in the training period. One might be concerned that differences in technology (such as upgrading of the vehicle fleet) or economic activity between the training and prediction sample violate this assumption (Silver et al. 2020). We address this concern adopting a difference-in-differences strategy that excludes any constant prediction bias from the estimated effects of the lockdown. As long as the variation of observed values around the true counterfactual mean is well reproduced, estimates will be valid. Furthermore, the learner is cross-validated on data from 2016 through 2019; thus, recent years are given more weight.

We estimate the average effect of the lockdown with the following equation:

$$
y_{i t}-\widehat{y}_{i t}=\alpha+\beta \text { Lockdown }+\epsilon_{i t}
$$


where $y_{i t}$ is concentration measured at monitor $i$ on day $t, \widehat{y}_{i t}$ is the predicted value, and Lockdown is a dummy equal to 1 during the lockdown and 0 prior to it. $\alpha$ captures any time-invariant bias of the predictor; $\beta$ is the parameter of interest; and $\epsilon_{i t}$ is a random term. The preferred specification then distinguishes treatment effects by type of monitoring station. $^{2}$ Since concentrations are consequential to the extent that they reflect exposure, we weight observations by population within 20 kilometers from monitors. ${ }^{3}$ We leave estimates of unweighted regressions, which yield qualitatively similar results, to the Supplementary information. To our knowledge, there is little guidance in the literature on how to estimate standard errors in this context properly. Thus, where reasonable, we cluster standard errors by monitor; where the number of clusters is small, we use robust heteroskedasticitystandard errors.

\footnotetext{
${ }^{2}$ Namely background, industrial, and traffic monitoring stations.
}

${ }^{3}$ Territory within 20 kilometers of two or more monitors is assigned to the closest monitor. The construction of population weights is described in more detail in Supplementary information. 


\subsection{Data sources}

We assemble a dataset of air pollution, atmospheric conditions and calendar variables for the period 2012 to 2020 for the Italian region of Lombardy. The region is the home to about 10 million people and is the first contributor to national GDP by size. Its natural geography is conducive to low winds and stable air masses throughout the cold season. Mountain ranges to the North, West and South effectively block transboundary air streams extending wintertime thermal inversions and aggravating pollution events. For exceeding recommended air quality thresholds, Italy has been fined and subject to infringement procedures by the European Commission. We describe the data sources and pollution trends in Lombardy.

\subsubsection{Air pollution}

Data for air pollution is collected, checked, and published by ARPA Lombardia, the regional environmental agency. ${ }^{4}$ We obtain readings for $\mathrm{NO}_{2}$ and total $\mathrm{PM}_{2.5}$ for background, traffic, and industrial stations as available. Hourly readings are averaged to daily readings. We exclude all monitoring stations that are not functioning during the lockdown or have been set up after 2015. Background stations account for about $60 \%$ of pollution monitors, traffic stations for about $30 \%$, and the remaining $10 \%$ is located in industrial areas.

Average yearly concentrations of $\mathrm{PM}_{2.5}$ in Milan, the region's capital, are systematically above the safety levels established by the WHO $\left(10 \mu \mathrm{g} / \mathrm{m}^{3}\right)$; from December to the end of February, daily concentrations average above $40 \mu \mathrm{g} / \mathrm{m}^{3}$. Average levels of $\mathrm{NO}_{2}$ during the period are also well above WHO safety standards.

\footnotetext{
${ }^{4}$ Both air pollution and weather data are publicly available at https://www.dati.lombardia.it/ stories/s/auv9-c2sj.
} 


\subsubsection{Weather data}

Data on weather conditions at weather stations throughout the region are also elaborated and made available by ARPA Lombardia. We retrieve the daily minimum and maximum temperature; average wind speed and wind direction; average relative humidity; and daily cumulative precipitation. We further include a host of atmospheric sounding indices measured at Milano Linate airport and made available by the University of Wyoming, namely Showalter index, Lifted index, SWEAT index, K index, and Cross Totals, and Vertical Totals indices. All atmospheric variables enter as predictors in the form of contemporaneous and lagged values. Although monitor data and atmospheric soundings have gone through quality checks at the source, we winsorize all atmospheric predictors at 1 and 99 percentiles to bound the influence of extreme values.

\subsubsection{Additional predictors}

The ratio of $\mathrm{PM}_{2.5}$ to $\mathrm{PM}_{10}$ in Lombardy is typically altered in presence of pollution transported from long distances. For instance, a mass of dust from the Caspian Sea reached Northern Italy in late March, substantially altering the ratio. We assume the $\mathrm{PM}_{2.5}$ to $\mathrm{PM}_{10}$ ratio is independent of the lockdown and include it among predictors as the concentration of $\mathrm{PM}_{2.5}$ is affected by such shocks. Additional predictors are calendar variables to capture trends over time and seasons. We include year, month, week of the year, day of the month, day of the week in the form of continuous variables as well as dummy variables. We further include sine functions of time to mimic seasonality.

\subsubsection{Population weights}

Population weights for monitoring stations reflect the population within 20 kilometers of monitors (Figure 3 in Supplementary information). Population data on a $1 \mathrm{~km}$ by $1 \mathrm{~km}$ 
grid comes from the Italian National Statistical Office (ISTAT).${ }^{5}$ Grid cells within less than 20 kilometers from two or more monitors are assigned to the closest one.

\subsection{Health impact assessment}

To compute the number of avoided deaths and years of life saved by the reduction in PM2.5, we follow Fowlie et al. (2019) and take all-cause mortality relative risk (RR) ratios for $\mathrm{PM}_{2.5}$ from two influential studies, Krewski et al. (2009) and Lepeule et al. (2012). In addition, we use the RR ratio recommended by the WHO (Henschel et al. (2013)) and adopted by the European Environment Agency (European Environment Agency 2019). For $\mathrm{NO}_{2}$, we only use the WHO recommendations. The calculation of avoided deaths and years of life saved from concentration-response functions is described in Supplementary Information A.1.

The more conservative estimates are based on Krewski et al. (2009), who report an hazard ratio 1.056 for an increase of $10 \mu \mathrm{g} / \mathrm{m}^{3}$ of $\mathrm{PM}_{2.5}$. Lepeule et al. (2012) estimate instead a larger hazard ratio of 1.14 for the same change in concentrations. The WHO recommends estimating the long-term impact of exposure to $\mathrm{PM}_{2.5}$ in adult populations using an RR of 1.062 for $10 \mu \mathrm{g} / \mathrm{m}^{3}$; it recommends an $\mathrm{RR}$ of 1.055 for $10 \mu \mathrm{g} / \mathrm{m}^{3}$ of $\mathrm{NO}_{2}$ above $20 \mu \mathrm{g} / \mathrm{m}^{3}$ in adult populations.

\section{Results and Discussion}

\subsection{Accuracy of predictions}

To assess the accuracy of predictions, we test the counterfactual against observed values during the pre-lockdown period from January 1 to February 22, which has not been used for

\footnotetext{
${ }^{5}$ The data is available at https://www.istat.it/it/files//2015/04/GEOSTAT_grid_POP_1K_IT_ 2011-22-10-2018.zip. Last accessed on July 23, 2020.
} 
training. Table 1 reports mean values of Pearson's correlation coefficient (Corr), mean bias (MB), normalized mean bias (nMB), and root mean square error (RMSE). As we ultimately compute the difference-in-differences between observed values and the counterfactual, we also report the centered RMSE (cRMSE) and the normalized centered RMSE (ncRMSE). ${ }^{6}$ For completeness, the table also includes statistics for the training set.

The correlation between observed and predicted values in the pre-lockdown period is 0.87 and 0.88 for $\mathrm{PM}_{2.5}$ and $\mathrm{NO}_{2}$, respectively. The counterfactual overestimates observed values by $1.34 \mu \mathrm{g} / \mathrm{m}^{3}\left(\mathrm{PM}_{2.5}\right)$ and $4.7 \mu \mathrm{g} / \mathrm{m}^{3}\left(\mathrm{NO}_{2}\right)$, thus motivating the use of a differencein-differences strategy. The centered RMSE is 30\% $\left(\mathrm{PM}_{2.5}\right)$ and $27 \%\left(\mathrm{NO}_{2}\right)$ of mean observed concentrations. A graphical summary of model predictive performance, Taylor diagrams, can be found in Supplementary information.

In air pollution forecasting, machine learning techniques are typically used to predict concentrations an hour to few days ahead, and studies that can be used as benchmark are scarce. To the best of our knowledge, Petetin et al. (2020) is the only work whose methodology and length of forecast are comparable. They use machine learning to build a counterfactual for $\mathrm{NO}_{2}$ concentrations in Spain during the COVID-19 lockdown. They report a normalized mean bias of $2 \%$ to $7 \%$, depending on the type of station, a correlation coefficient of 0.71 to 0.75 , and normalized RMSE of $28 \%$ to $32 \%$. Compared to their study, our algorithm better mimics variation around the mean, than the mean itself. However, in our estimation strategy, any constant bias is captured by the constant in Equation 1.

${ }^{6}$ The centered RMSE is computed as $\left[1 / N \sum\left(\widehat{y}_{i}-\overline{\widehat{y}}-y_{i}+\bar{y}\right)^{2}\right]^{1 / 2}$. 
Table 1: Accuracy of predictions, average values across monitors

\begin{tabular}{llcccccc}
\hline Pollutant & Dataset & Corr & MB & nMB & RMSE & cRMSE & ncRMSE \\
\hline NO2 & Train & 1 & .004 & 0 & 276 & .275 & .008 \\
NO2 & Test & .875 & -4.672 & -.159 & 9.961 & 8.088 & .261 \\
PM2.5 & Train & .999 & 0 & 0 & .443 & .443 & .015 \\
PM2.5 & Test & .871 & -1.335 & -.049 & 8.764 & 8.476 & .295 \\
\hline
\end{tabular}

Notes: Corr: Pearson's correlation coefficient. MB: Mean bias, where negative values indicate observed values below predicted values. $n M B$ : Normalized mean bias. RMSE: Root mean squared error. $n R M S E$ : Normalized RMSE. $c R M S E$ : Centered RMSE. ncRMSE: Normalized centered RMSE. Mean bias, RMSE and centered RMSE are expressed in $\mu g / \mathrm{m}^{3}$. Mean bias, RMSE and centered RMSE are normalized dividing by mean observed concentrations. The centered RMSE is computed as $\left[1 / N \sum\left(\widehat{y}_{i}-\overline{\hat{y}}-y_{i}+\bar{y}\right)^{2}\right]^{1 / 2}$. 


\subsection{Effect of the lockdown on air pollution}

Following the lockdown, air quality in Lombardy improved only partially. Figure 2 plots the population-weighted observed and counterfactual values for $\mathrm{PM}_{2.5}$ (Figure 2a) and $\mathrm{NO}_{2}$ (Figure $2 \mathrm{~b}$ ). $\mathrm{NO}_{2}$ at background stations reached levels below the yearly limit set by the WHO Air Quality Guidelines. However, background concentrations of $\mathrm{PM}_{2.5}$ still exceeded the daily limit of $25 \mu \mathrm{g} / \mathrm{m}^{3}$ every one in four days.

The counterfactual well mimics observed values in the pre-lockdown period, corroborating the validity of the statistical approach. In contrast, a gap between observed and counterfactual values is evident as restrictions are tightened. We show in Supplementary information that the method outperforms a linear regression.

Suggestive evidence of the effect of the lockdown on concentrations of $\mathrm{NO}_{2}$, which in Lombardy largely originate from motor vehicles, is visible from the week of February 25, consistent with the reduction in mobility documented in Figure 1a. The effect on $\mathrm{PM}_{2.5}$ only appears as non-essential economic activities are halted in Lombardy and the rest of Italy, and is smaller in magnitude. 
(a)

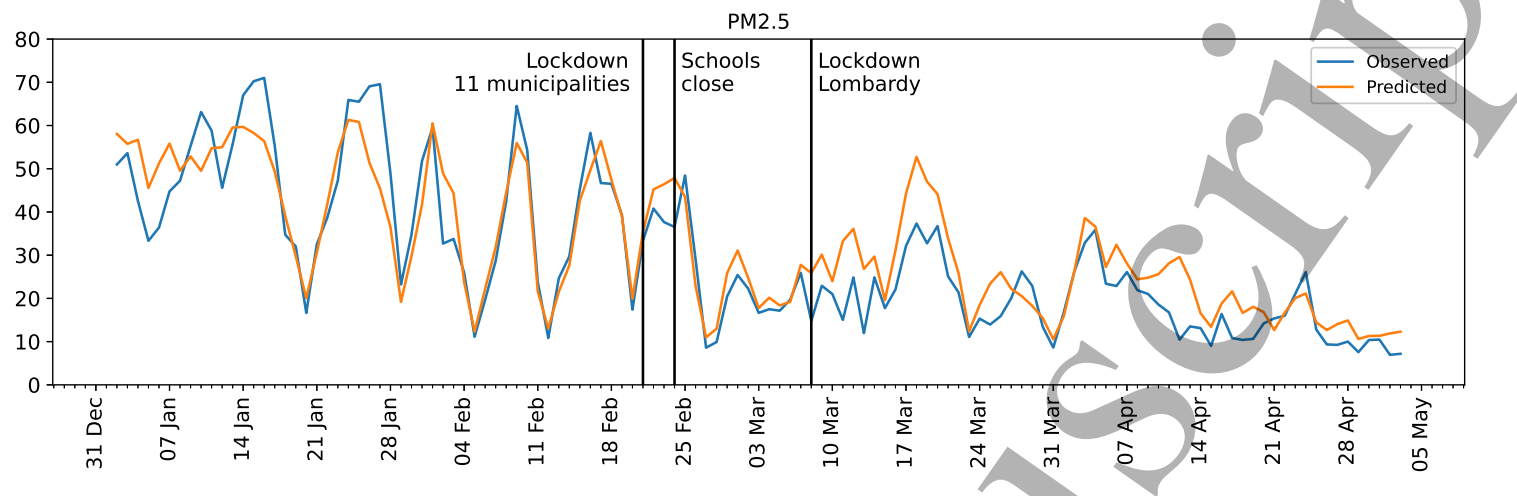

(b)

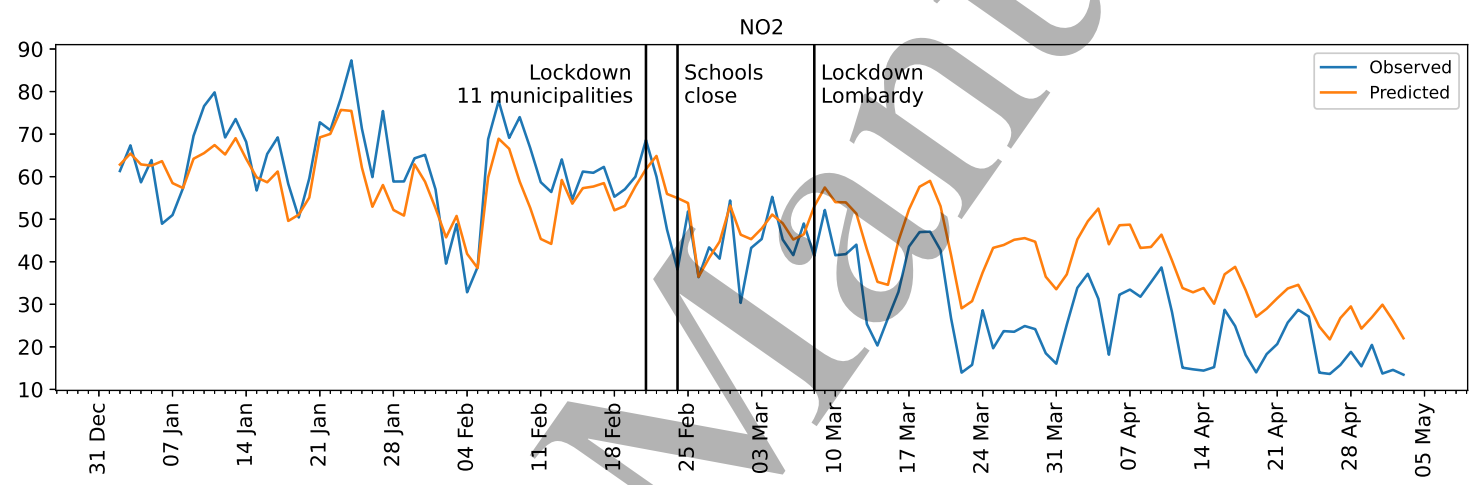

Figure 2: Population-weighted average of observed and counterfactual values. a, $\mathrm{PM}_{2.5}$. b, $\mathrm{NO}_{2}$. Population is measured within 20 kilometers of a monitoring station. Territory within less than 20 kilometers from two or more monitors is assigned to the closest one.

The lockdown may have affected $\mathrm{PM}_{2.5}$ concentrations mainly through two channels: the reduction of primary $\mathrm{PM}_{2.5}$ emissions, such as black and organic carbon, and reduction of precursors of secondary $\mathrm{PM}_{2.5}$. We remark that $\mathrm{NO}_{2}$ is a precursor of secondary $\mathrm{PM}_{2.5}$; a reduction in $\mathrm{NO}_{2}$ may, therefore, lead to a decline in $\mathrm{PM}_{2.5}$. However, as data on $\mathrm{PM}_{2.5}$ 
composition is insufficient, we cannot quantify the contribution of $\mathrm{NO}_{2}$ to the reductions in $\mathrm{PM}_{2.5}$ concentrations. ${ }^{7}$ Therefore we treat both pollutants independently.

We estimate a population-weighted version of Equation 1 in Methods and report results in Table 2. Results of unweighted regressions are qualitatively similar and can be found in Supplementary information. From February 22 to May 4, the lockdown has on average reduced daily concentrations of $\mathrm{PM}_{2.5}$ and $\mathrm{NO}_{2}$ by $5.32 \mu \mathrm{g} / \mathrm{m}^{3}$ and $13.56 \mu \mathrm{g} / \mathrm{m}^{3}$. That is a reduction of $21.8 \%$ and $35.6 \%$, respectively, from the average levels that would have been observed had not the epidemic broken out.

Next, our preferred specification distinguishes effects of the lockdown by type of monitor. Background monitors are located where concentrations are representative of the ambient exposure of the general population; industrial monitors are located in the proximity of industrial sites or industrial sources; traffic monitors are located near a major road.

Population-weighted average background concentrations of $\mathrm{PM}_{2.5}$ decreased by 3.84 $\mu \mathrm{g} / \mathrm{m}^{3}$ from $24.42 \mu \mathrm{g} / \mathrm{m}^{3}$ (Table 3). ${ }^{8}$ The reduction was almost twice as large in monitored industrial sites and near major roads. Background concentrations of $\mathrm{NO}_{2}$ dropped by 10.85 $\mu \mathrm{g} / \mathrm{m}^{3}$ from $33.22 \mu \mathrm{g} / \mathrm{m}^{3}$, by $10.66 \mu \mathrm{g} / \mathrm{m}^{3}$ near monitored industrial sites and by 15.85 $\mu \mathrm{g} / \mathrm{m}^{3}$ more at major roads

\footnotetext{
${ }^{7}$ At the time of writing, data on composition of $\mathrm{PM}_{2.5}$ has not been released. Data on composition of $\mathrm{PM}_{10}$ is available only for 3 monitoring station.

${ }^{8}$ The very low number of monitors by type makes clustered standard errors inappropriate. We thus use robust standard errors.
} 
Table 2: Population-weighted regression

Notes: Regression weighted by population within 20 kilometers of a monitoring station. Territory within less than 20 kilometers from two or more monitors is assigned to the closest one. The dependent variable is the difference between the observed values and the counterfactual. Lockdown is a dummy variable equal to 0 from January 1 , 2020 to February 22, and equal to 1 after February 22, 2020. Average baseline concentration is the population-weighted average of counterfactual values during the lockdown, less the constant in case the latter is statistically significant at $10 \%$. Standard errors, in brackets, are clustered by monitor. ${ }^{*} \mathrm{p}<0.1,{ }^{* *} \mathrm{p}<0.05,{ }^{* * *} \mathrm{p}<0.01$. 
Table 3: Heterogeneous effects by type of monitoring station

\begin{tabular}{|c|c|c|c|c|c|c|}
\hline & \multicolumn{6}{|c|}{$\Delta_{\text {Observed,Counter factual }}$} \\
\hline & \multicolumn{3}{|c|}{ PM 2.5} & \multirow[b]{2}{*}{ Background } & \multirow[b]{2}{*}{ Industrial } & \multirow[b]{2}{*}{ Traffic } \\
\hline & Background & Industrial & Traffic & & & \\
\hline \multirow[t]{2}{*}{ Lockdown } & $-3.84^{* * *}$ & $-7.39^{* * *}$ & $-7.28^{* * *}$ & & $-10.66^{* * *}$ & $-15.85^{* * *}$ \\
\hline & $(0.97)$ & $(1.54)$ & $(1.20)$ & & $(0.96)$ & $(0.75)$ \\
\hline \multirow[t]{2}{*}{ Constant } & -1.26 & $5.18^{* * *}$ & $2.79^{* *}$ & & $7.29^{* * *}$ & $4.04^{* * *}$ \\
\hline & $(0.84)$ & $(1.37)$ & $(1.07)$ & $(0.49)$ & $(0.84)$ & $(0.63)$ \\
\hline Average baseline concentration & 24.42 & 27.99 & & 3.22 & 31.93 & 46.67 \\
\hline Number of monitors & 18 & 2 & & 53 & 6 & 24 \\
\hline Observations & 2117 & 244 & 1194 & 6483 & 731 & 2870 \\
\hline
\end{tabular}

Notes: Regression weighted by population within 20 kilometers of a monitoring station. Territory within less than 20 kilometers from two or more monitors is assigned to the closest one. The dependent variable is the difference between the observed values and the counterfactual. Lockdown is a dummy variable equal to 0 from January 1, 2020 to February 22, and equal to 1 after February 22, 2020. Average baseline concentration is the population-weighted average of counterfactual values during the lockdown, less the constant in case the latter is statistically significant at $10 \%$, Robust standard errors are in brackets. ${ }^{*} \mathrm{p}<0.1,{ }^{* *} \mathrm{p}<0.05$, $* * * \mathrm{p}<0.01$. 


\subsection{Human health benefits}

As the reduction in road transport and the slowing of economic activity reduced toxic emissions, the burden of pollutants on human health eased. For calculations, we use the estimated change in concentrations at background stations. Avoided deaths and YLS should be considered a lower-bound estimate of total health benefits avoided deaths.

The reduction in $\mathrm{PM}_{2.5}$ prevented 10.2 to 24.8 premature deaths per 100,000 individuals and saved 72.1 to 175.9 years of life per 100,000 individuals, depending on the concentration-response function (Table 4). The reduction in $\mathrm{NO}_{2}$ prevented 28.8 premature deaths and saved 203.7 years of life per 100,000 individuals. Given the high correlation between concentrations of $\mathrm{PM}_{2.5}$ and $\mathrm{NO}_{2}$, the concentration-response function of these pollutants are interdependent. It is recommended that ayoided deaths and YLS be not aggregated across pollutants, lest incurring in partial double counting.

As a comparison, in Italy in 2016 for every 100,000 individuals, there have been 96.6 premature deaths attributable to PM2.5 and 24.1 attributable to $\mathrm{NO}_{2}$, or 23.8 and 5.9 premature deaths in three months, respectively (European Environment Agency 2019). Since most of the premature deaths happen in the more polluted North of Italy, including Lombardy, the lockdown has temporarily reduced the cost of pollution by a substantial amount.

We compare the results against the number of deaths and the years of life lost (YLL) related to COVID-19 in Lombardy during the same period, computed from patient-level data. $^{9}$ In Lombardy, from February 22 to May 3 2020, every 100,000 people 155 died after testing positive for COVID-19 and 1891 years of life have been directly lost to the virus. Avoided deaths from the reduction in $\mathrm{PM}_{2.5}$ are $6.5 \%$ to $16 \%$ of COVID-19 deaths; YLS

\footnotetext{
${ }^{9}$ Data on the individual COVID-19 patients has been shared by regional health officers under an institutional agreement.
} 
Table 4: Avoided premature deaths and years of life saved per 100,000 in Lombardy due to improved air quality during lockdown.

\begin{tabular}{llccc}
\hline & Pollutant & Source of HR & Hazard ratio & Avoided deaths \\
\hline \multirow{2}{*}{ Avoided deaths } & NO2 & EEA/WHO & 1.055 & 28.8 \\
& PM 2.5 & EEA/WHO & 1.062 & 11.3 \\
& PM 2.5 & Krewski et al. (2009) & 1.056 & 10.2 \\
& PM 2.5 & Lepeule et al. (2012) & 1.14 & 24.8 \\
Years of life saved & NO2 & EEA/WHO & 1.055 & 203.7 \\
& PM 2.5 & EEA/WHO & 1.062 & 79.7 \\
& PM 2.5 & Krewski et al. (2009) & 1.056 & 72.1 \\
& PM 2.5 & Lepeule et al. (2012) & 1.14 & 175.9 \\
\hline
\end{tabular}

In Lombardy, from February 22 to May 3 2020, every 100,000 people 155 died after testing positive for COVID-19 and 1891 years of life have been directly lost to the virus. The hazard ratio is the ratio of two concentration-response functions, or hazard rates, between a high and alow concentration differing by 10 $\mu \mathrm{g} / \mathrm{m}^{3}$. Avoided premature deaths are calculated using the population-weighted change in concentrations at background stations.

are $3.8 \%$ to $9.3 \%$ of YLL to COVID-19. Avoided deaths from the reduction in $\mathrm{NO}_{2}$ are $18.6 \%$ of COVID-19 deaths; YLS are $10.8 \%$ of YLL to COVID-19. 


\section{Conclusions}

The dramatic reduction in emissions of airborne pollutants that has come with the response to COVID-19 provides a unique natural experiment to assess the sensitivity of pollutants concentrations and health to emissions. We estimate a substantial yet partial improvement in air quality in Lombardy following the outbreak, and suggest that the improvement originates primarily from the reduction of road transport; and to a lesser degree from the reduction in industrial activity. Important sources of emissions as heating systems and agriculture have not been substantially affected by the outbreak.

The methodology used to build the counterfactual does not require identifying comparable but unaffected regions, but relies on the assumption of emissions absent the lockdown following historical variation around the mean. The approach is not limited to this case study, but can be applied in a variety of settings due to the increasing and reliable availability of pollution and weather data.

Finally, we are nowhere near suggesting the pandemic has been beneficial for the affected communities, yet the health benefits from improved air quality are noticeable. While global pandemics are rare phenomena, exposure to unhealthy levels of toxic air pollutants is the rule, including in affluent regions of the world such as the one considered here. This paper has emphasized some of the health benefits of cleaner air, but also highlighted the variety of emissions sources and the need for a broader policy response to solve Europe's biggest environmental health risk.

\section{Acknowledgements}

The authors would like to thank participants to the RFF-CMCC webinar and Guido Lanzani for useful comments, and ARPA Lombabrdia for sharing data and their expertise. This 
research received no specific grant from any funding agency in the public, commercial, or not-for-profit sectors. The authors declare that there is no conflict of interests regarding the publication of this paper.

\section{Data availability statement}

Pollution data and weather at monitoring stations is openly available at https://www . dati.lombardia.it/ and available upon request from the authors. Data on atmospheric sounding is openly available at http://weather . uwyo .edu/upperair/sounding.html. The population grid file is openly available at https://www.istat.it/it/files//2015/04/ GEOSTAT_grid_POP_1K_IT_2011-22-10-2018.zip.

\section{References}

Amini, H., Nhung, N. T. T., Schindler, C., Yunesian, M., Hosseini, V., Shamsipour, M., Hassanvand, M. S., Mohammadi, Y., Farzadfar, F., Vicedo-Cabrera, A. M., et al. (2019). Short-term associations between daily mortality and ambient particulate matter, nitrogen dioxide, and the air quality index in a Middle Eastern megacity. Environmental Pollution, 254:113121.

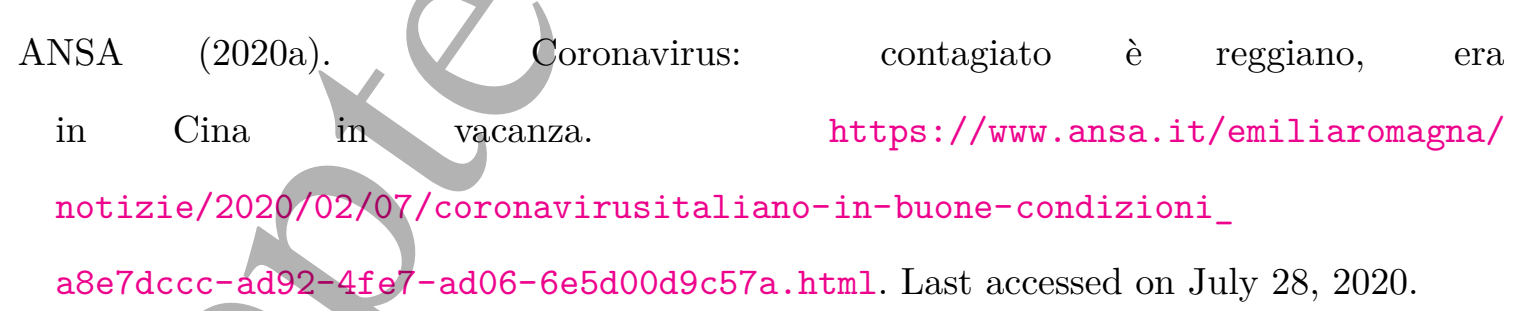

ANSA (2020b). Coronavirus: coppia Taiwan in Toscana dal 26 al 29 gennaio. https://www.ansa.it/toscana/notizie/2020/02/09/ 
ANSA (2020d). Coronavirus, sedici nuovi contagiati. Due sono in Veneto. Altri 8 casi a Codogno, 5 operatori sanitari. https://www.ansa.it/ lombardia/notizie/2020/02/21/coronavirus-sedici-nuovi-contagiati. -due-sono-in-veneto.-altri-8-casi-a-codogno-5-operatori-sanitari_ c7a81b85-4370-46b8-a2db-9a7a4df05d90.htm1. Last accessed on July 28, 2020.

Apple (2020). COVID-19 Mobility Trends Reports. Data retrieved from https://www . apple.com/covid19/mobility. Last accessed on September 22, 2020.

Chen, T. and Guestrin, C. (2016). XGBoost. A Scalable Tree Boosting System. In Proceedings of the 22nd ACM SIGKDD International Conference on Knowledge Discovery and Data Mining, pages 785-794.

Cole, M. A., Elliott, R. J.R., and Liu, B. (2020). The Impact of the Wuhan Covid-19 Lockdown on Air Pollution and Health: A Machine Learning and Augmented Synthetic Control Approach. Environmental and Resource Economics, 76(4):553-580.

Dechezleprêtre, A., Rivers, N., and Stadler, B. (2019). The economic cost of air pollution: Evidence from europe. Technical report, OECD Publishing. 
Deryugina, T., Heutel, G., Miller, N. H., Molitor, D., and Reif, J. (2019). The Mortality and Medical Costs of Air Pollution: Evidence from Changes in Wind Direction. American Economic Review, 109(12):4178-4219.

Duan, Y., Liao, Y., Li, H., Yan, S., Zhao, Z., Yu, S., Fu, Y., Wang, Z., Yin, P., Cheng, J., et al. (2019). Effect of changes in season and temperature on cardiovascular mortality associated with nitrogen dioxide air pollution in Shenzhen, China. Science of The Total Environment, 697:134051.

Ebenstein, A., Fan, M., Greenstone, M., He, G., and Zhou, M. (2017). New evidence on the impact of sustained exposure to air pollution on life expectancy from China's Huai River Policy. Proceedings of the National Academy of Sciences, 114(39):10384-10389.

Ebenstein, A., Lavy, V., and Roth, S. (2016). The long-run economic consequences of high-stakes examinations: Evidence from transitory variation in pollution. American Economic Journal: Applied Economics, 8(4):36-65.

European Commission v. Italian Republic (2012). Judgment of the Court (First Chamber), 19 December 2012, C-68/11, ECLI:EU:C:2012:815, Court of Justice of the European Union.

European Commission v. Italian Republic (2019). Application of 26 July 2019, C-573/19, Court of Justice of the European Union.

European Commission v. Italian Republic (2020). Judgment of the Court (Grand Chamber) of 10 November 2020, C-644/18, ECLI:EU:C:2020:895, Court of Justice of the European Union.

European Environment Agency (2019). Air quality in Europe - 2019 report. 
Fowlie, M., Rubin, E., and Walker, R. (2019). Bringing satellite-based air quality estimates down to earth. AEA Papers and Proceedings, 109:283-88.

Friedman, J. H. (2001). Greedy function approximation: a gradient boosting machine. Annals of statistics, pages 1189-1232.

Google (2020). COVID-19 Community Mobility Reports. Data retrieved from https: //www.google.com/covid19/mobility/. Last accessed on June 27, 2020.

Graff Zivin, J. and Neidell, M. (2012). The Impact of Pollution on Worker Productivity. American Economic Review, 102(7):3652-3673.

Guidelli, M. (2020). Coronavirus in Italia: scattato l'isolamento dei focolai, 43 varchi e 500 uomini. ANSA.it. https://WWw.ansa,it/canale_saluteebenessere/ notizie/sanita/2020/02/23/coronavirus-in-italia-aumentano-i-contagi. -scuole-chiuse-in-lombardia-e-veneto.-stop-al-carnevale-di-venezia_ 40e888b6-8418-406a-9771-7a6c3c0b45fd. html. Last accessed on July 28, 2020.

Guo, S., Hu, M., Zamora, M. L., Peng, J., Shang, D., Zheng, J., Du, Z., Wu, Z., Shao, M., Zeng, L., Molina, M. J., and Zhang, R. (2014). Elucidating severe urban haze formation in China. Proceedings of the National Academy of Sciences, 111(49):17373-17378.

He, G., Pan, Y., and Tanaka, T. (2020). The short-term impacts of COVID-19 lockdown on urban air pollution in China. Nature Sustainability.

He, J., Liu, H., and Salvo, A. (2019). Severe Air Pollution and Labor Productivity: Evidence from Industrial Towns in China. American Economic Journal: Applied Economics, 11(1):173-201. 
Henschel, S., Chan, G., Organization, W. H., et al. (2013). Health risks of air pollution in europe-hrapie project: New emerging risks to health from air pollution-results from the survey of experts.

INEMAR (2017). INEMAR - Inventario Emissioni Aria. Last accessed on June 15, 2020. Data retrieved from http://inemar . arpalombardia.it/inemar/webdata/main. seam? $\operatorname{cid}=22157$.

Kahn, M. E. and Li, P. (2020). Air pollution lowers high skill public sector worker productivity in China. Environmental Research Letters, 15(8):084003.

Krewski, D., Jerrett, M., Burnett, R. T., Ma, R., Hughes, E., Shi, Y., Turner, M. C., Pope III, C. A., Thurston, G., Calle, E. E., et al. (2009). Extended follow-up and spatial analysis of the American Cancer Society study linking particulate air pollution and mortality. Number 140. Health Effects Institute Boston, MA.

Kroll, J. H., Heald, C. L., Cappa, C. D., Farmer, D. K., Fry, J. L., Murphy, J. G., and Steiner, A. L. (2020). The complex chemical effects of COVID-19 shutdowns on air quality. Nature Chemistry, 12(9):777-779.

La Repubblica (2020). Coronavirus, in dieci comuni lombardi: 50 mila persone costrette a restare in casa. Quarantena all'ospedale milanese di Baggio. https://milano.repubblica.it/cronaca/2020/02/21/news/coronavirus_ codogno_castiglione_d_adda_contagiati_misure_sicurezza-249154447/. Last accessed on July 28, 2020.

Lelieveld, J., Evans, J. S., Fnais, M., Giannadaki, D., and Pozzer, A. (2015). The contribution of outdoor air pollution sources to premature mortality on a global scale. Nature, $525(7569): 367-371$. 
Lepeule, J., Laden, F., Dockery, D., and Schwartz, J. (2012). Chronic exposure to fine particles and mortality: an extended follow-up of the Harvard Six Cities study from 1974 to 2009. Environmental health perspectives, 120(7):965-970.

Mills, I. C., Atkinson, R. W., Kang, S., Walton, H., and Anderson, H. (2015). Quantitative systematic review of the associations between short-term exposure to nitrogen dioxide and mortality and hospital admissions. BMJ open, 5(5).

Ministro della Salute (2020a). Ordinanza 21 febbraio 2020 Ulteriori misure profilattiche contro la diffusione della malattia infettiva COVID-19.(20A01220) . Gazzetta Ufficiale Serie Generale n.44 del 22-02-2020.

Ministro della Salute (2020b). Ordinanza 23 febbraio 2020 Mísure urgenti in materia di contenimento e gestione dell'emergenza epídemiologica da COVID-19. Regione Lombardia. (20A01273). Gazzetta Ufficiale Serie Generale n.47 del 25-02-2020.

Petetin, H., Bowdalo, D., Soret, A., Guevara, M., Jorba, O., Serradell, K., and Pérez García-Pando, C. (2020). Meteorology-normalized impact of COVID-19 lockdown upon NO2 pollution in Spain. Atmospheric Chemistry and Physics Discussions, 2020:1-29.

Pope, C. A. I. and Dockery, D. W. (2006). Health Effects of Fine Particulate Air Pollution: Lines that Connect. Journal of the Air \& Waste Management Association, 56(6):709-742.

Presidente del Consiglio dei Ministri (2020a). Decreto del Presidente del Consiglio dei Ministri 8 marzo 2020 Ulteriori disposizioni attuative del decreto-legge 23 febbraio 2020, n. 6 , recante misure urgenti in materia di contenimento e gestione dell'emergenza epidemiologica da COVID-19. (20A01522). Gazzetta Ufficiale Serie Generale n.59 del 08-03-2020.

Presidente del Consiglio dei Ministri (2020b). Decreto del Presidente del Consiglio dei Ministri 1 marzo 2020 Ulteriori disposizioni attuative del decreto-legge 23 febbraio 2020, n. 
6, recante misure urgenti in materia di contenimento e gestione dell'emergenza epidemiologica da COVID-19. (20A01381). Gazzetta Ufficiale Serie Generale n.52 del 01-03-2020.

Presidente del Consiglio dei Ministri (2020c). Decreto del Presidente del Consiglio dei Ministri 25 febbraio 2010. Ulteriori disposizioni attuative del decreto-legge 23 febbraio 2020, n. 6, recante misure urgenti in materia di contenimento e gestione dell'emergenza epidemiologica da COVID-19. Gazzetta Ufficiale Serie Generale n.47 del 25-02-2020.

Presidente del Consiglio dei Ministri (2020d). Decreto del Presidente del Consiglio dei Ministri 25 febbraio 2020 Ulteriori disposizioni attuative del decreto-legge 23 febbraio 2020, n. 6, recante misure urgenti in materia di contenimento e gestione dell'emergenza epidemiologica da COVID-19. (20A01278). Gazzetta Ufficiale Serie Generale n.47 del 25-02-2020.

Presidente del Consiglio dei Ministri (2020e). Decreto del Presidente del Consiglio dei Minsitri 22 marzo 2020 Ulteriori disposizioni attuative del decreto-legge 23 febbraio 2020, n. 6, recante misure urgenti in materia di contenimento e gestione dell'emergenza epidemiologica da COVID-19, applicabili sull'intero territorio nazionale. (20A01807). Gazzetta Ufficiale Serie Generale n.76 del 22-03-2020.

Presidente della Repubblica (2020). Decreto-legge 23 febbraio 2020, n. 6 Misure urgenti in materia di, contenimento e gestione dell'emergenza epidemiologica da COVID19 (20G00020). Decreto-Legge convertito con modificazioni dalla L. 5 marzo 2020, n. 13 (in G.U. 09/03/2020, n. 61). Gazzetta Ufficiale Serie Generale n.45 del 23-022020. https://wWw.gazzettaufficiale.it/eli/id/2020/02/23/20G00020/sg\%7D\% 7BGazzettaUfficiale. 
Presidenza del Consiglio dei Ministri (2020). IoRestoaCasa, misure per il contenimento e gestione dell'emergenza epidemiologica. http://www.governo.it/it/ iorestoacasa-misure-governo.

Protezione Civile (2020). Dati COVID-19 Italia - Public repository of the Protezione Civile. Last accessed on July 28, 2020.

Silver, B., He, X., Arnold, S. R., and Spracklen, D. V. (2020). The impact of COVID-19 control measures on air quality in China. Environmental Research Letters, 15(8):084021.

Taylor, K. E. (2001). Summarizing multiple aspects of model performance in a single diagram. Journal of Geophysical Research: Atmospheres, 106(D7):7183-7192.

TERNA (2020). Transparency Report. Data retrieved from https://www.terna.it/it/ sistema-elettrico/transparency-report/download-center. Last accessed on June 28, 2020.

Vandyck, T., Keramidas, K., Kitous, A., Spadaro, J. V., Dingenen, R. V., Holland, M., and Saveyn, B. (2018). Air quality co-benefits for human health and agriculture counterbalance costs to meet Paris Agreement pledges. Nature Communications, 9(1).

Zhang, X., Chen, X., and Zhang, X. (2018). The impact of exposure to air pollution on cognitive performance. Proceedings of the National Academy of Sciences, 115(37):91939197. 


\section{A Supplementary information}

\section{A.1 Years of life saved}

Concentration-response functions are typically estimated with log-linear regressions of mortality risk on pollutants of the form $\ln (y)=\alpha+\beta C$, so that $y=A e^{\beta C}$. The change in mortality risk from $y^{\prime}$ to $y^{\prime \prime}$ is

$$
\begin{aligned}
y^{\prime}-y^{\prime \prime} & =A\left(e^{\beta C^{\prime}}-e^{\beta C^{\prime \prime}}\right) \\
& =A e^{\beta C^{\prime}}\left(1-e^{\beta\left(C^{\prime \prime}-C^{\prime}\right)}\right) \\
& =y^{\prime}\left(1-\frac{1}{e^{\beta\left(C^{\prime}-C^{\prime \prime}\right)}}\right)
\end{aligned}
$$

with $A=e^{\alpha}$. Here $y^{\prime}$ is the baseline mortality risk and $e^{\beta\left(C^{\prime}-C^{\prime \prime}\right)}$ is the $\operatorname{RR}$. The $\beta$ coefficient is not typically reported, but is easily found as $\beta=\ln (R R) / 10$.

For each gender $g$ and age group $a$ above 30, we multiply the change in mortality risk from the baseline by the number of individuals in Lombardy of that gender and age group $\left(N_{g, a}\right) .{ }^{10}$ This gives us the number of avoided deaths for a year-long reduction in pollutants. We then multiply this number by gender- and age-specific life expectancy to obtain the YLS.

$$
\begin{aligned}
\text { Avoided Deaths } s_{g, a} & =y_{g, a}^{\prime} \cdot\left(1-\frac{1}{e^{\beta\left(C^{\prime}-C^{\prime \prime}\right)}}\right) \cdot N_{g, a} \cdot \frac{1}{6} \\
Y L S_{g, a} & =\text { Avoided Deaths } s_{g, a} \cdot \text { Life Expectancy } \text { Ev }, a \\
Y L S & =\sum_{g} \sum_{a} Y L S_{g, a}
\end{aligned}
$$

\footnotetext{
${ }^{10}$ The benefits from reductions in $\mathrm{NO}_{2}$ are set to zero for values below $20 \mu \mathrm{g} / \mathrm{m}^{3}$, as recommended by Henschel et al. (2013).
} 
It should be noted that we are assuming that avoided deaths and years of life saved by a two-month improvement in air quality are equivalent to a sixth of the benefits of a year-long improvement. In addition, we assume that the gains are linear in reductions of concentrations. ${ }^{11}$

Gender- and age-group specific baseline mortality risk, population size and life expectancy come from mortality tables for Lombardy compiled by the Italian National Statistical Office (ISTAT). Avoided deaths and YLS are computed using the lockdown on pollution $\left(C^{\prime}-C^{\prime \prime}\right)$ estimated at background stations.

\section{A.2 Accuracy of linear regression for construction of counterfactuals}

We show a linear regression model does not perform as well as the machine learning algorithm used for the main results. For every monitoring station, we regress daily concentrations on a vector of daily weather summaries, namely daily cumulative precipitation, average temperature, average wind speed and average wind direction, in 2012 through 2019 (Equation A.2.1). We then use the estimated coefficients to predict concentrations in 2020 before and throughout the lockdown (Equation A.2.2). Finally, we assess the accuracy of predictions during the pre-lockdown period from January 1 to February 21, 2020. Precipitation, temperature, wind speed and direction on day $t$ at any given pollution monitor are interpolated with inverse distance weight from the three closest weather stations within 0.2 degrees from the monitor.

$$
\begin{gathered}
y_{t_{2012-2019}}=\alpha+\beta^{\prime} \text { Weather } t_{t_{2012-2019}}+\epsilon_{t_{2012-2019}} \\
\widehat{y}_{t_{2020}}=\widehat{\alpha}+\widehat{\beta}^{\prime} \text { Weather }{ }_{t_{2020}}
\end{gathered}
$$

\footnotetext{
${ }^{11}$ This is in line with Henschel et al. (2013), who recommend a linear concentrations-response function.
} 
Observed and predicted population-weighted average concentrations are displayed in Figure A.3. While approximating pre-lockdown values on average, the predictions fail to capture a non-negligible portion of the variability. The validity of predictions based on linear regressions is especially poor for $\mathrm{PM}_{2.5}$. The same conclusions can be drawn examining average accuracy measures for linear regression predictions in Table/A.5.

Table A.5: Accuracy of liner regression predictions, average values across monitors

\begin{tabular}{|c|c|c|c|c|c|c|}
\hline Pollutant & Dataset & Corr & MB & nMB & RMSE & ncRMSE \\
\hline $\mathrm{NO} 2$ & Train & 0.71 & 0 & 0 & 9.7 & 0.33 \\
\hline NO2 & Test & 0.7 & -5.09 & -0.16 & 11.45 & 0.37 \\
\hline PM2.5 & Train & 0.63 & 0 & & 12.21 & 0.53 \\
\hline PM2.5 & Test & 0.59 & 0.35 & 0.01 & 14.21 & 0.5 \\
\hline
\end{tabular}

Notes: Corr: Pearson's correlation coefficient. MB: Mean bias, where negative values indicate observed values below predicted values. $n M B$ : Normalized mean bias. $R M S E$ : Root mean squared error. $n R M S E$ : Normalized RMSE. cRMSE: Centered/RMSE. ncRMSE: Normalized centered RMSE. Mean bias, RMSE and centered RMSE are expressed in $\mu \mathrm{g} / \mathrm{m}^{3}$. Mean bias, RMSE and centered RMSE are normalized dividing by mean observed concentrations. The centered RMSE is computed as $\left[1 / N \sum\left(\widehat{y}_{i}-\overline{\widehat{y}}-y_{i}+\bar{y}\right)^{2}\right]^{1 / 2}$. 
(a)

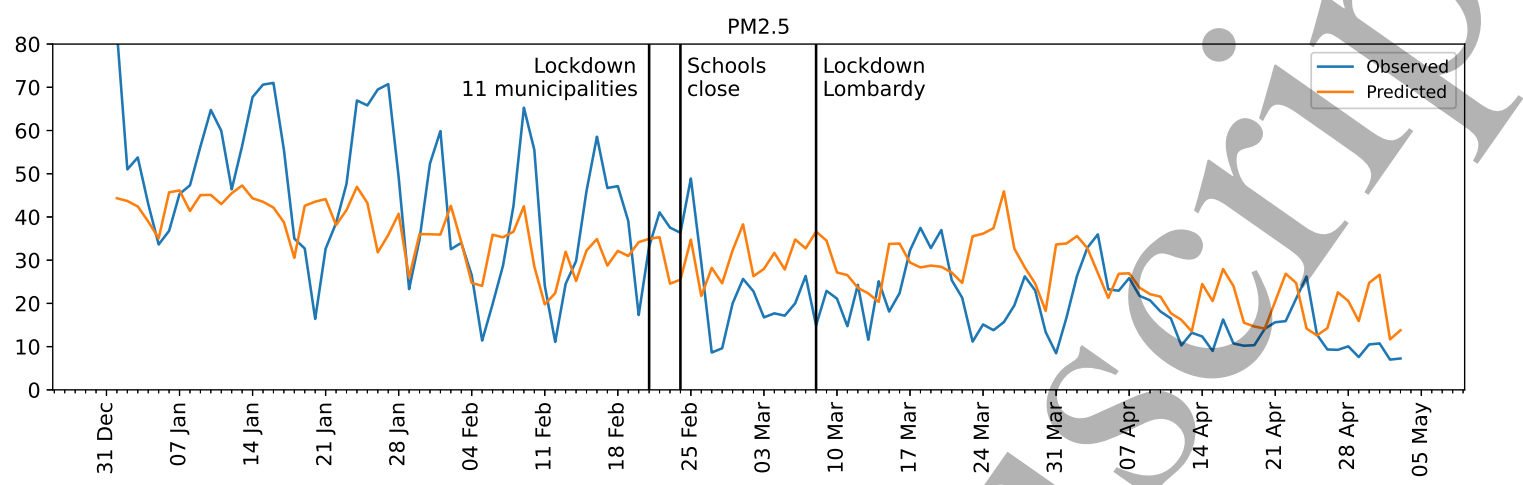

(b)

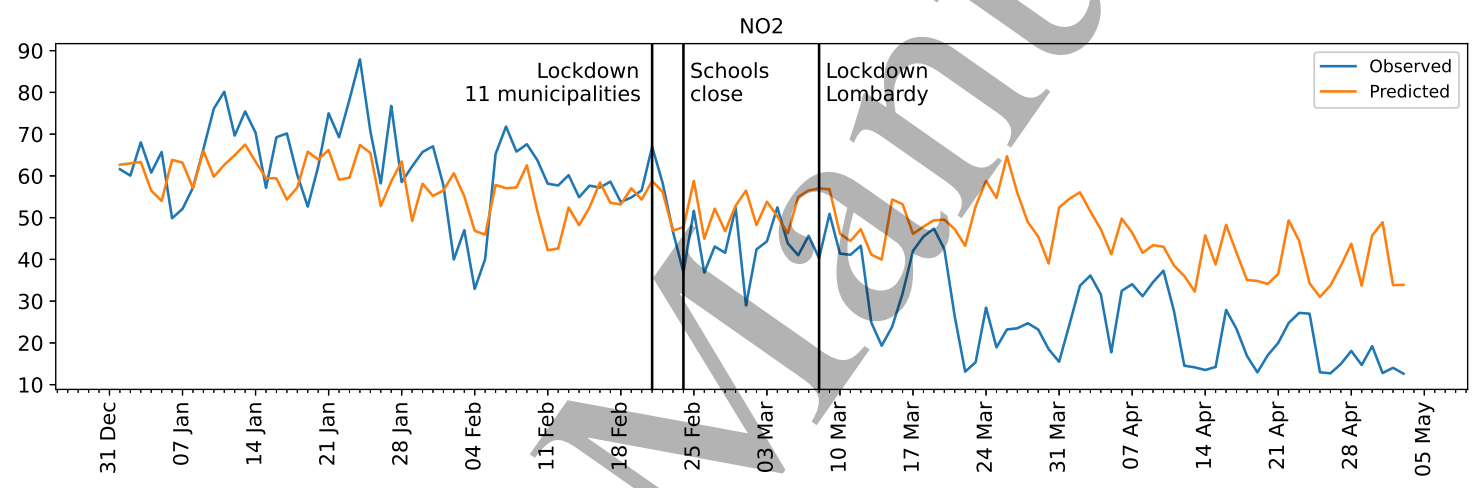

Figure A.3: Population-weighted average of observed and counterfactual values built with linear regression models. $\mathbf{a}, \mathrm{PM}_{2.5}$. b, $\mathrm{NO}_{2}$. Population is measured within 20 kilometers of a monitoring station. Territory within less than 20 kilometers from two or more monitors is assigned to the closest one. 


\section{A.3 Supplementary tables}

Table A.6: Pollution monitors by type.

\begin{tabular}{lccc}
\hline Pollutant & Type of monitor & $\begin{array}{c}\text { Number of } \\
\text { municipalities }\end{array}$ & Number of monitors \\
\hline NO2 & Background & 50 & 53 \\
NO2 & Industrial & 6 & 6 \\
NO2 & Traffic & 20 & 24 \\
PM2.5 & Background & 18 & 18 \\
PM2.5 & Industrial & 2 & 10 \\
PM2.5 & Traffic & 10 & \\
\hline
\end{tabular}

Background stations measure pollutions concentrations that are representative of the average exposure of the general population, or vegetation. Industrial stations are located in close proximity to an industrial area or an industrial source. Traffic stations are located in close proximity to a single major road. 
Table A.7: Unweighted regression

Notes: Unweighted regression. The dependent variable is the difference between the observed values and the counterfactual. Lockdown is a dummy variable equal to 0 from January 1, 2020 to February 22, and equal to 1 after February 22, 2020. Average baseline concentration is the average of counterfactual values during the lockdown, less the constant in case the latter is statistically significant at $10 \%$. Standard errors, in brackets, are clustered by monitor. ${ }^{*} \mathrm{p}<0.1, * *$ $\mathrm{p}<0.05, * * * \mathrm{p}<0.01$.

(1)

(2)

Constant

(0.65)

\begin{tabular}{lll}
\hline Average baseline concentration & 25.58 & 38.14 \\
Observations & 3555 & 10084 \\
\hline
\end{tabular}

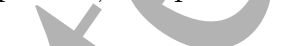


Table A.8: Heterogeneous effects by type of monitoring station - unweighted regression 


\section{A.4 Supplementary figures}

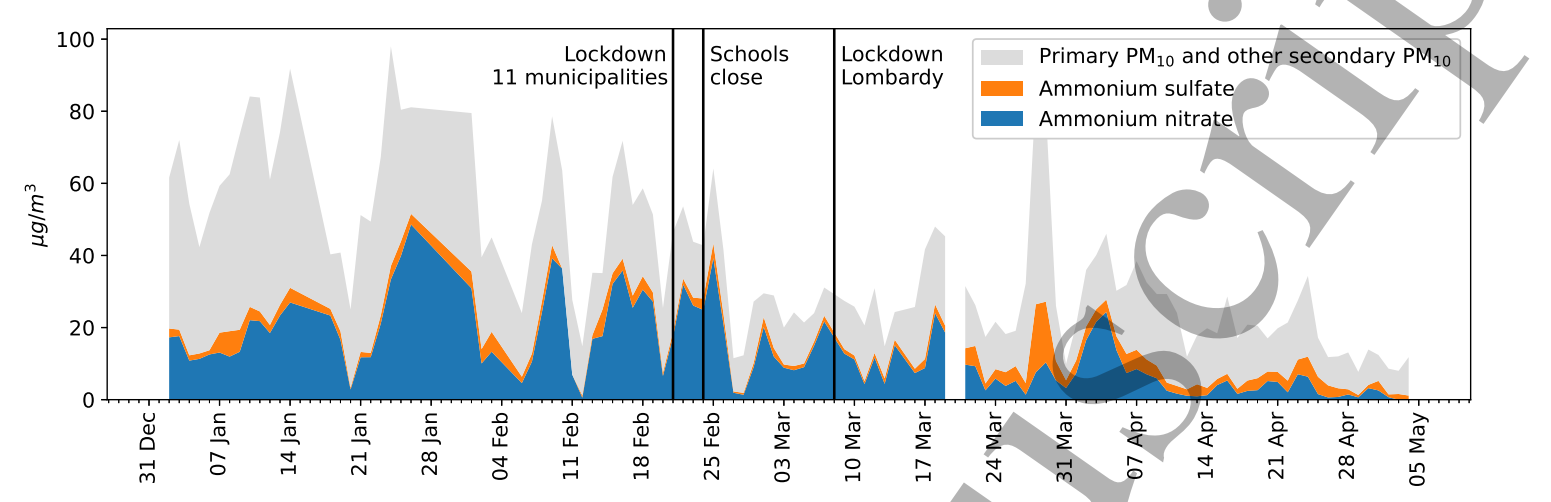

Figure A.4: Composition of background $\mathrm{PM}_{10}$ in Milan, Lombardy. Source: ARPA Lombardia. 


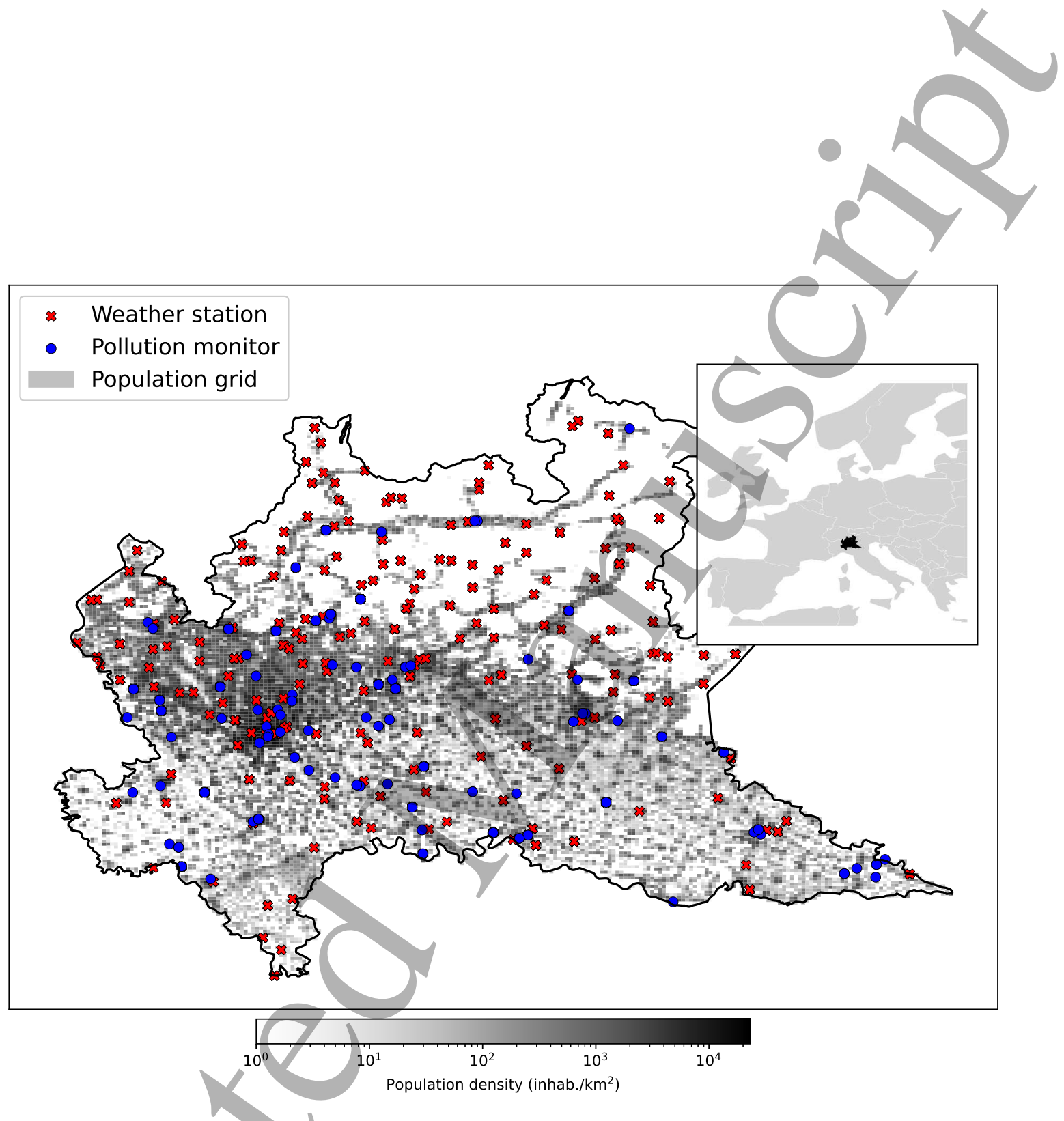

Figure A.5: Location of pollution monitors and weather stations in Lombardy over a $1 \mathrm{~km}$ by $1 \mathrm{~km}$ population grid. 
(a) $\mathrm{PM}_{2.5}$

Figure A.6: Taylor diagrams are a practical way to display different dimensions of model predictive performance (Taylor 2001) . Each circle represents the prediction of a model, that is, in this case, a monitoring station for the pre-lockdown period from January 1 to February 22. Isocurves from the origin outward measure the standard deviation of a model's predictions relative to the standard deviation of the observed values. The azimut measures Pearson's correlation coefficient. The ideal model prediction has a relative standard deviation of 1 and a correlation coefficient of 1 , and is marked by the red diamond. We do not show the RMSE, as is practice in Taylor diagrams, because it is graphically incompatible with the relative standard deviation. 
Figures A.8, A.9, and A.10 show the observed concentrations, predicted concentrations, and estimated reductions of $\mathrm{PM}_{2.5}$ at background monitoring stations averaged over two weeks. Figure A.11 shows the local premature deaths avoided by the reduction in $\mathrm{PM}_{2.5}$.
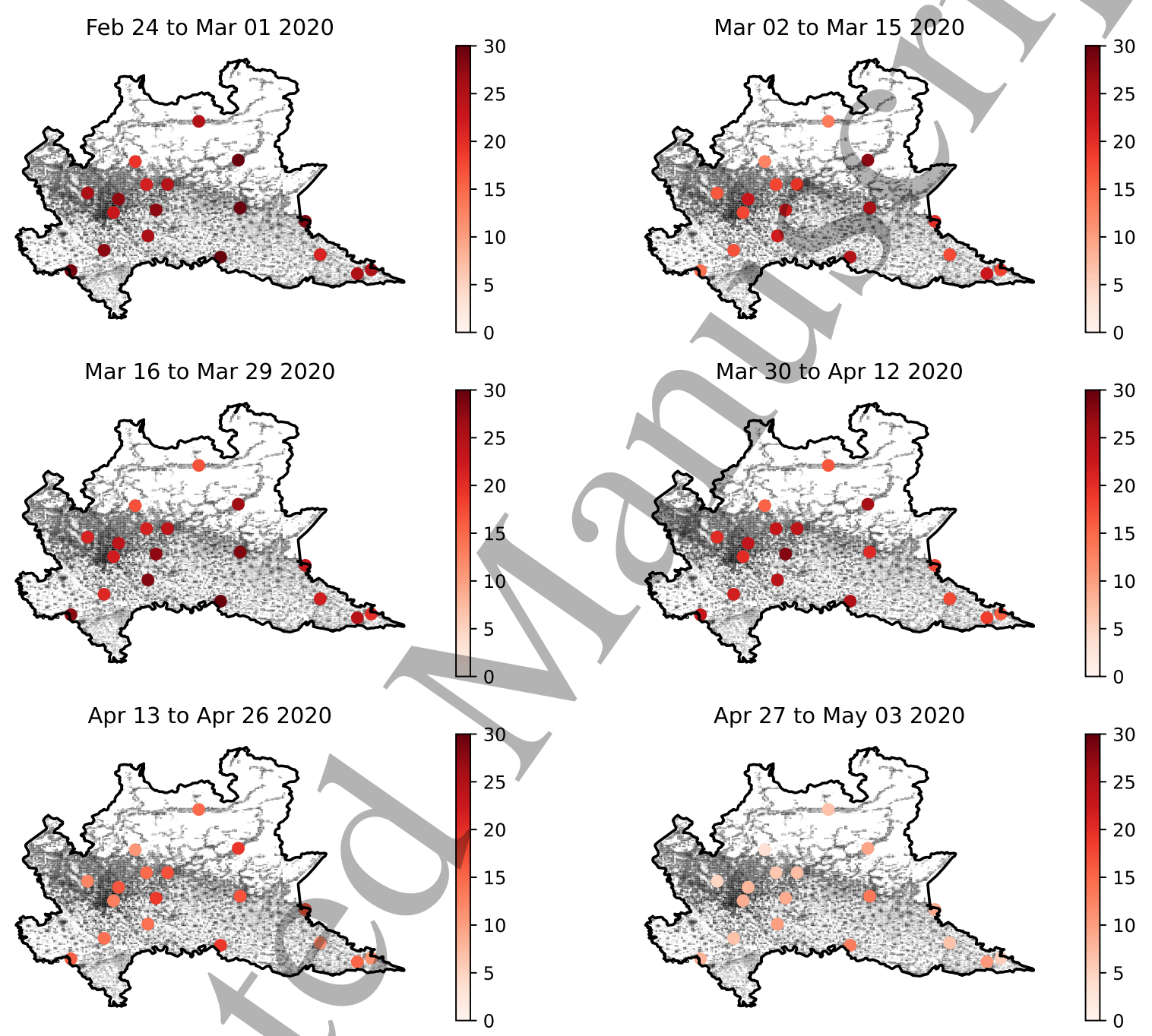


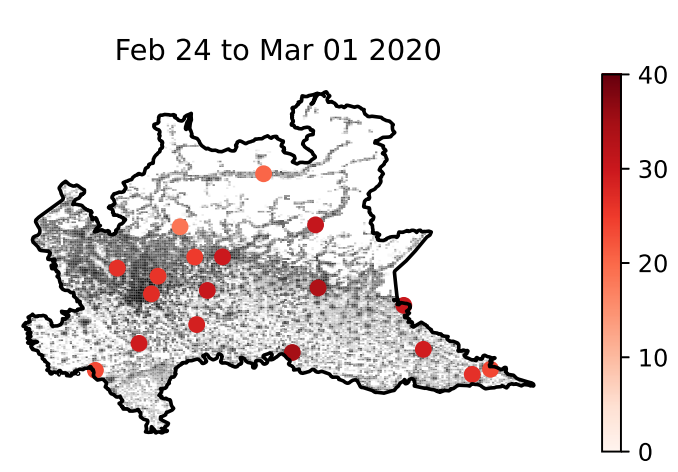

Mar 16 to Mar 292020

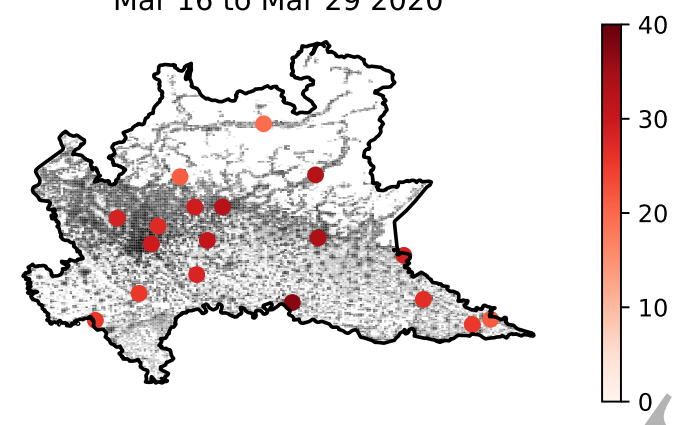

Apr 13 to Apr 262020

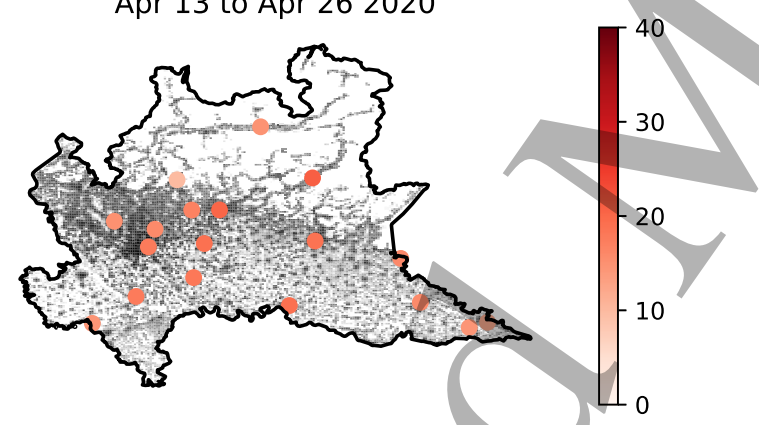

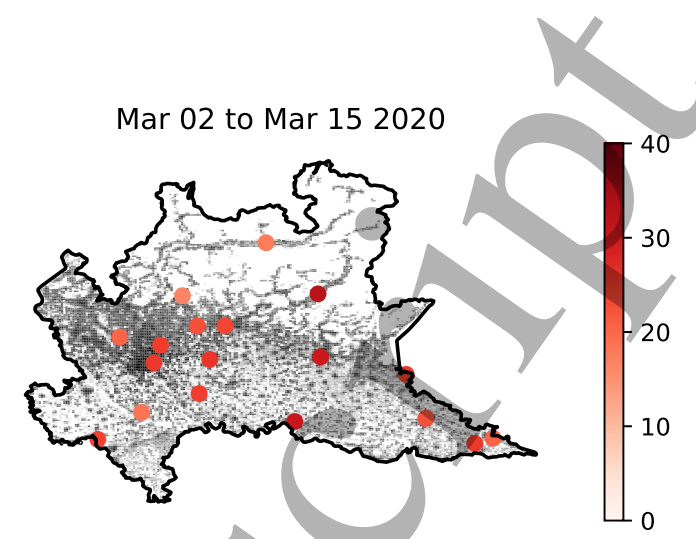

Mar 30 to Apr 122020

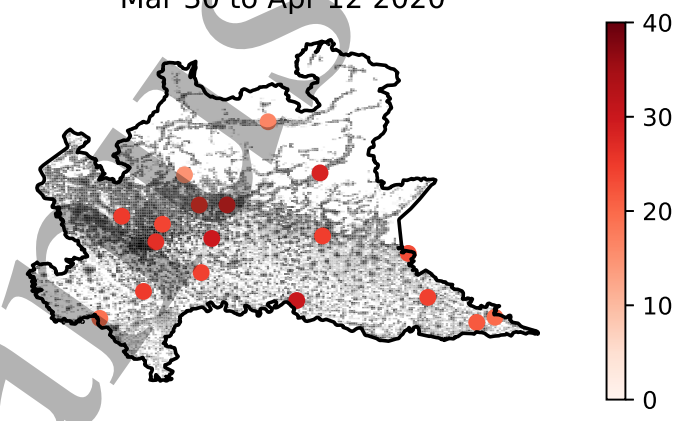

Apr 27 to May 032020

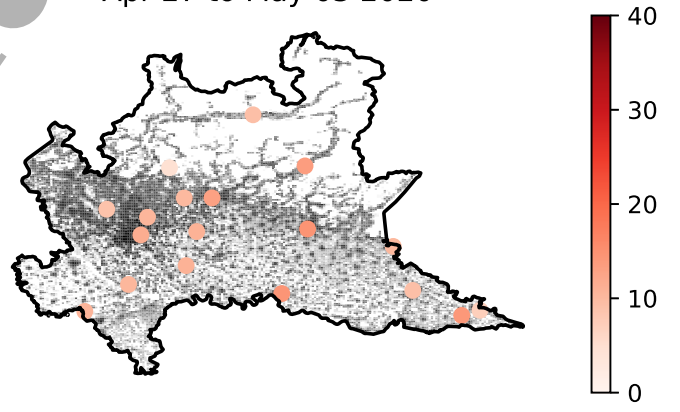

Figure A.9: Predicted concentrations of $\mathrm{PM}_{2.5}$ in $\mu \mathrm{g} / \mathrm{m}^{3}$ at background monitoring stations during the lockdown. Grey pixel are a $1 \mathrm{~km}$ by $1 \mathrm{~km}$ population grid. 
Feb 24 to Mar 012020

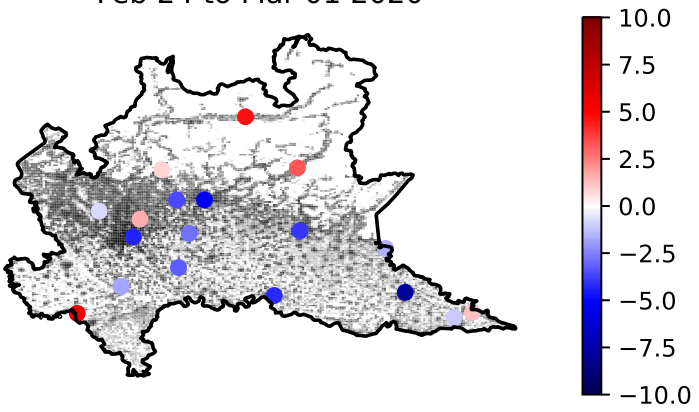

Mar 16 to Mar 292020

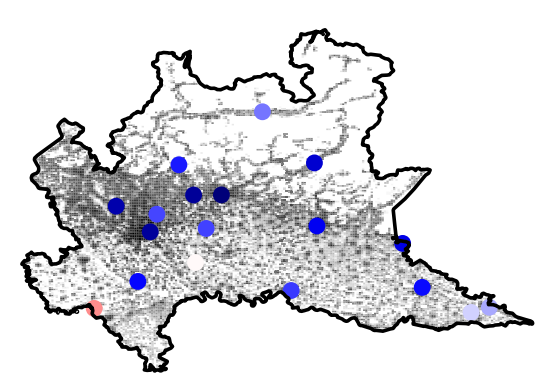

Apr 13 to Apr 262020

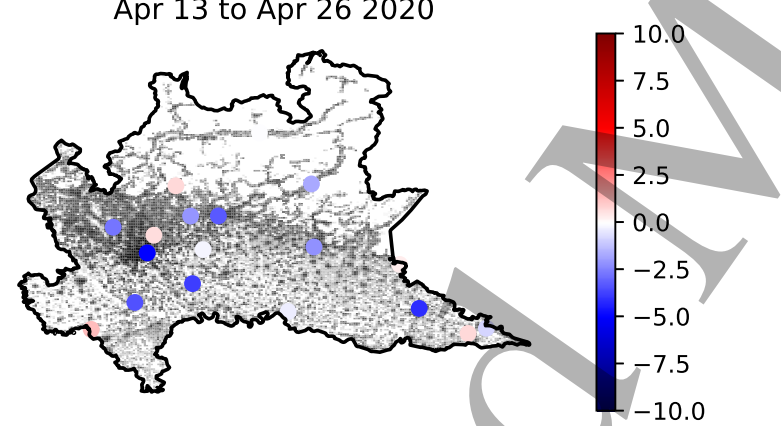

Mar 02 to Mar 152020

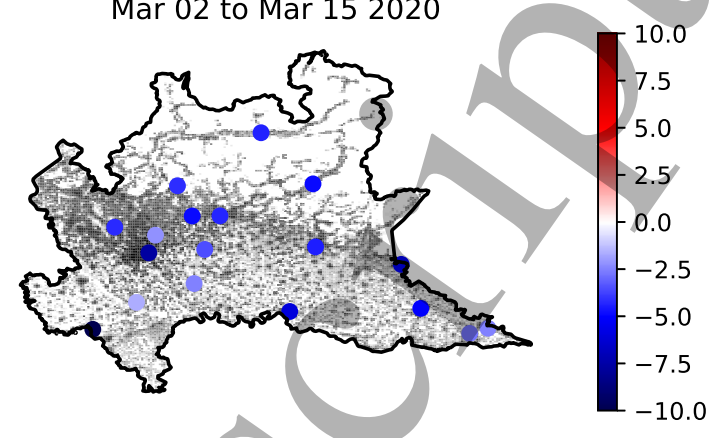

Mar 30 to Apr 122020

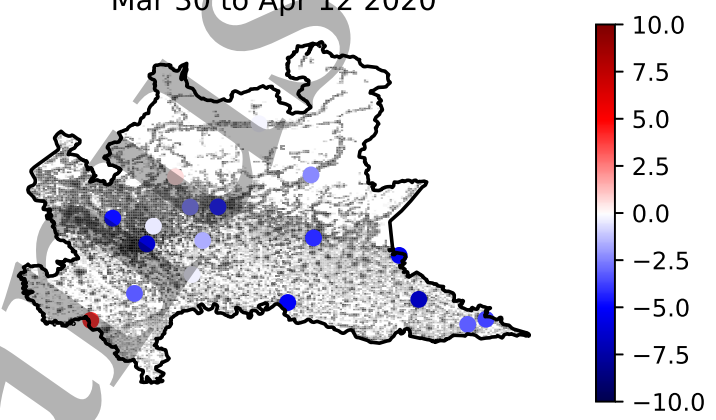

Apr 27 to May 032020

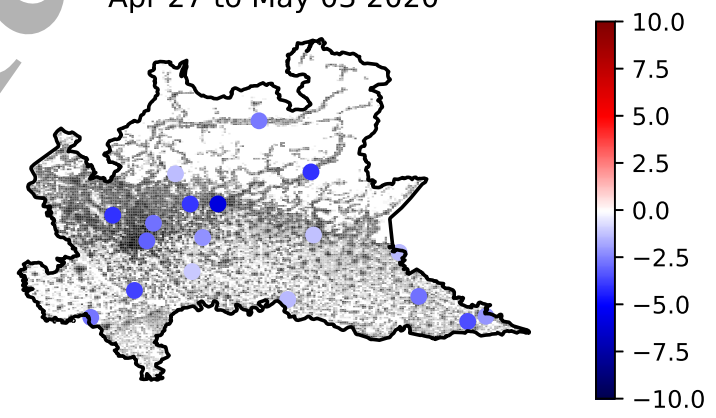

Figure A.10: Estimated reductions in concentrations of $\mathrm{PM}_{2.5}$ in $\mu \mathrm{g} / \mathrm{m}^{3}$ at background monitoring stations during the lockdown. Grey pixel are a $1 \mathrm{~km}$ by $1 \mathrm{~km}$ population grid. 
Figure A.11: Premature deaths avoided by reductions in $\mathrm{PM}_{2.5}$ within $20 \mathrm{~km}$ of background monitoring stations. Territory within less than 20 kilometers from two or more monitors is assigned to the closest one.

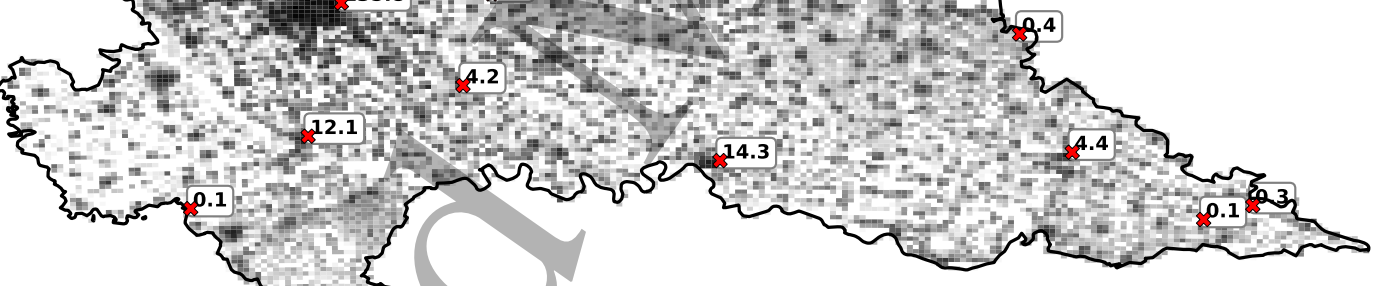

48
49
50
51
52
53
54
55
56
57
58
59


Figures A.12, A.13, and A.14 show the observed concentrations, predicted concentrations, and estimated reductions of $\mathrm{NO}_{2}$ at background stations averaged over two weeks. Figure A.15 shows the local premature deaths avoided by the reduction in $\mathrm{NO}_{2}$.
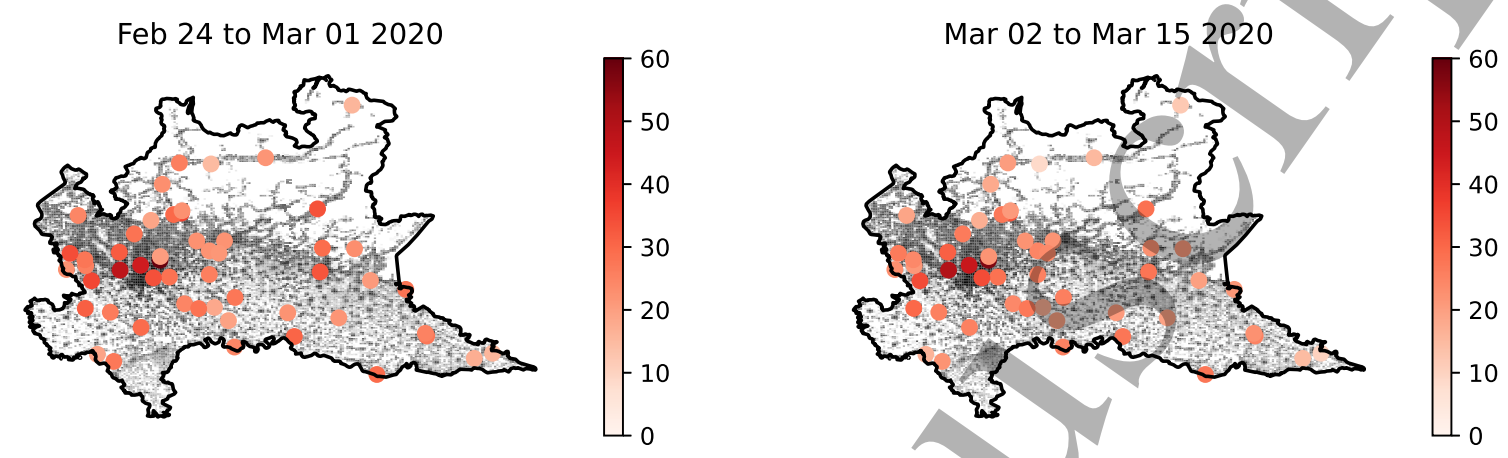

Mar 16 to Mar 292020
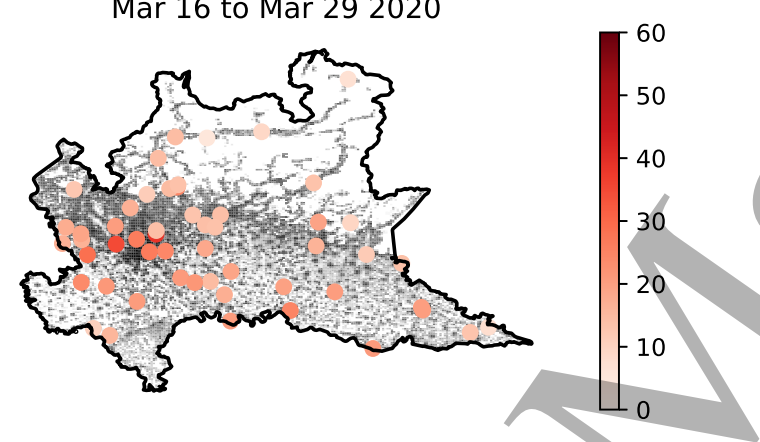

Mar 30 to Apr 122020
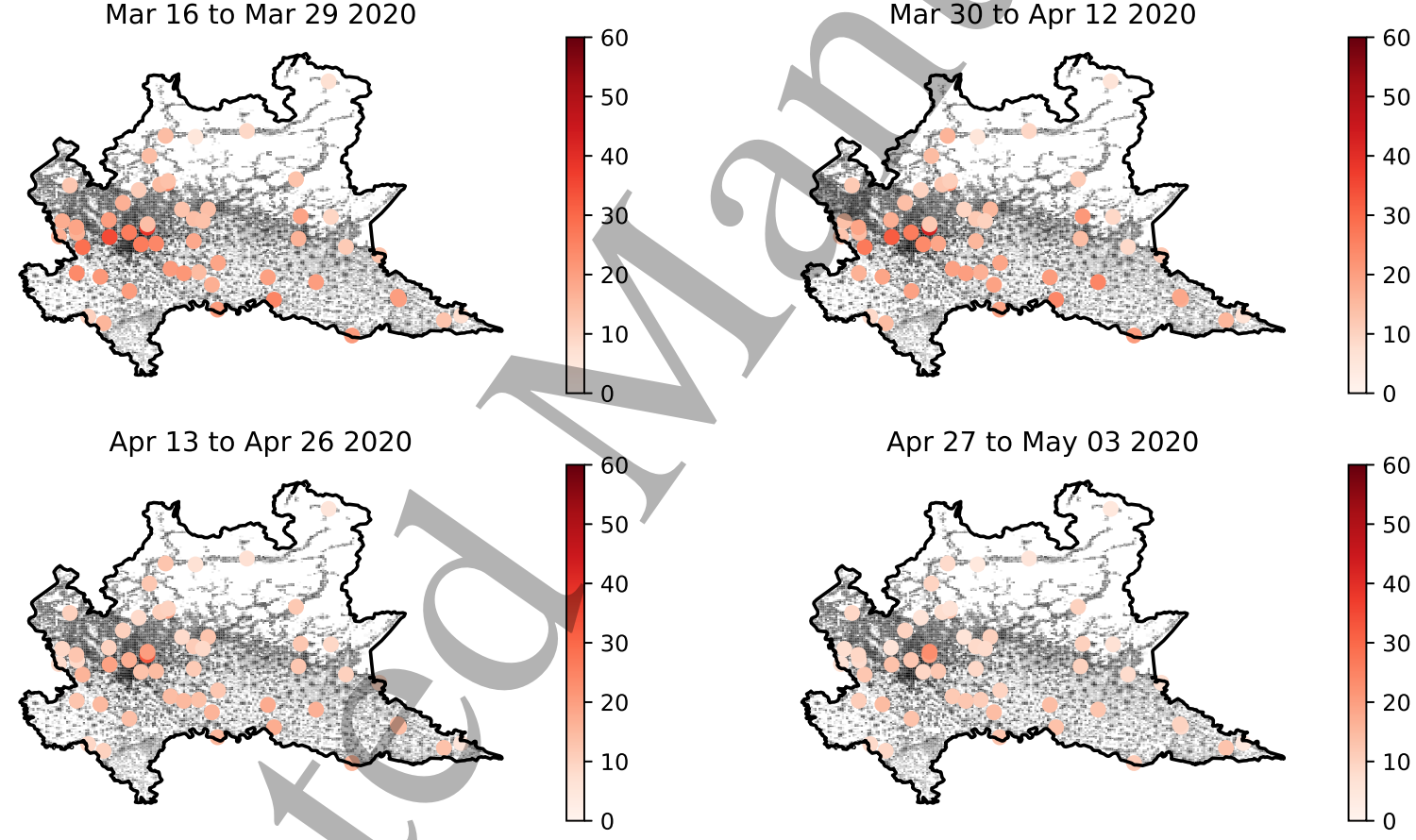

Apr 27 to May 032020

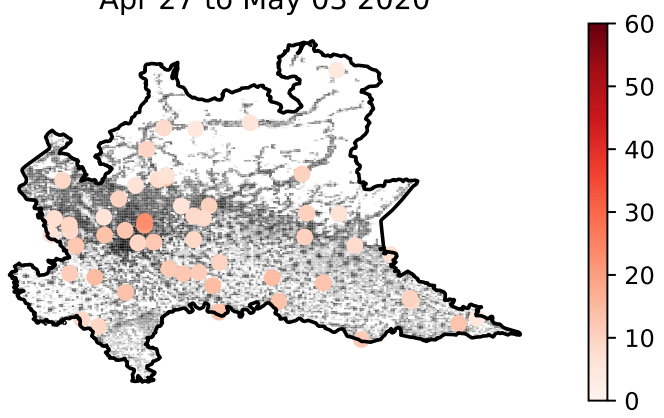

Figure A.12: Observed concentrations of $\mathrm{NO}_{2}$ in $\mu \mathrm{g} / \mathrm{m}^{3}$ at background monitoring stations averaged over two weeks. Grey pixel are a $1 \mathrm{~km}$ by $1 \mathrm{~km}$ population grid. 
Feb 24 to Mar 012020

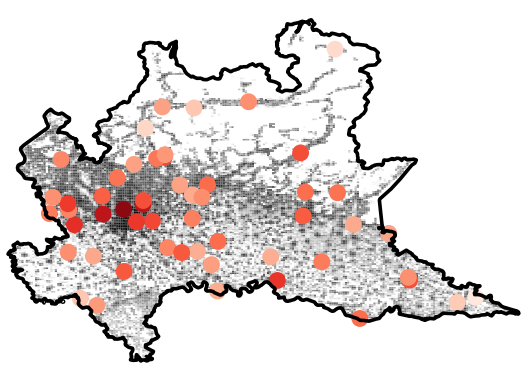

Mar 16 to Mar 292020

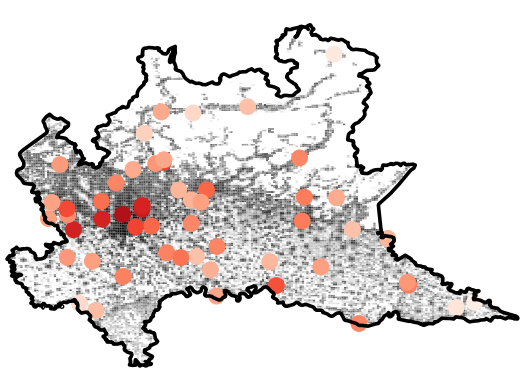

Apr 13 to Apr 262020
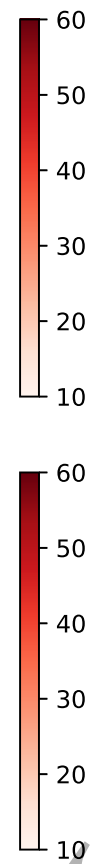

10
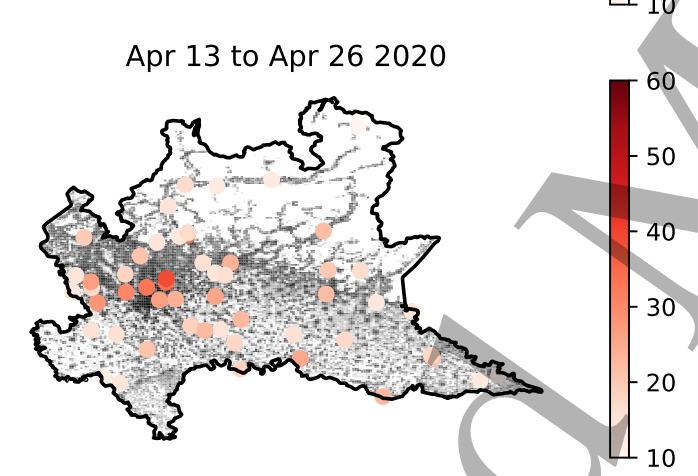

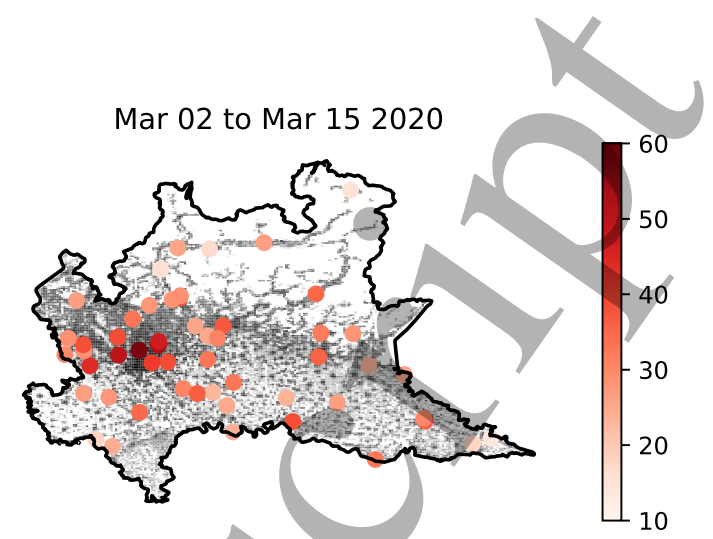

Mar 30 to Apr 122020

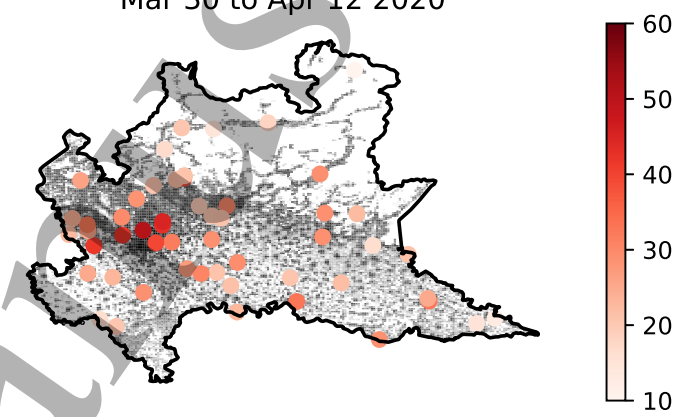

Apr 27 to May 032020

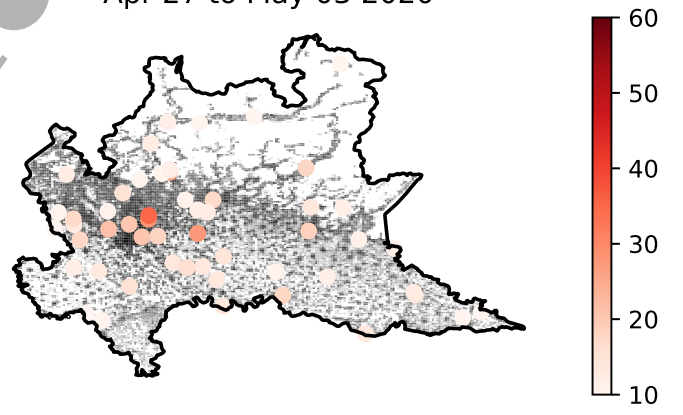

Figure A.13: Predicted concentrations of $\mathrm{NO}_{2}$ in $\mu \mathrm{g} / \mathrm{m}^{3}$ at background monitoring stations during the lockdown. Grey pixel are a $1 \mathrm{~km}$ by $1 \mathrm{~km}$ population grid. 
Feb 24 to Mar 012020

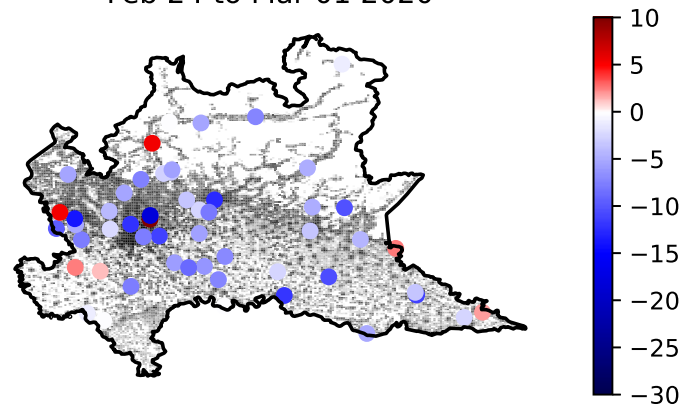

Mar 16 to Mar 292020

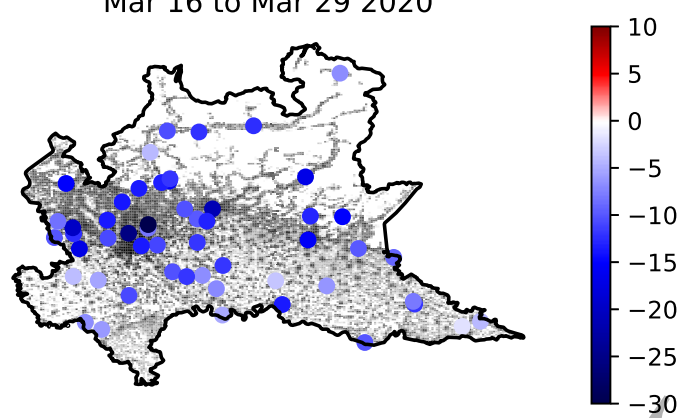

Apr 13 to Apr 262020

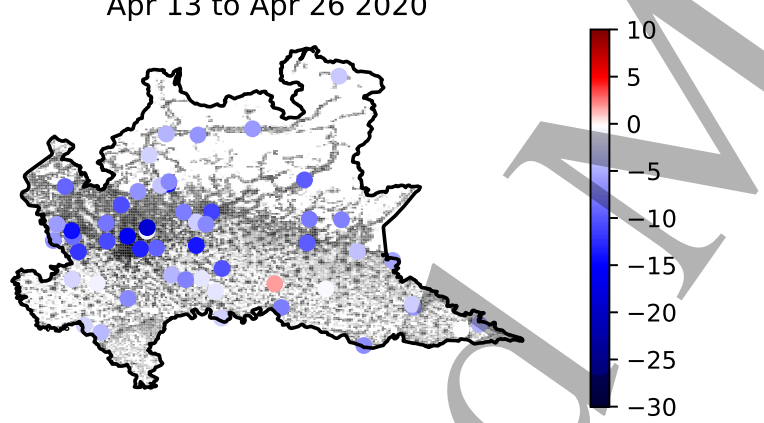

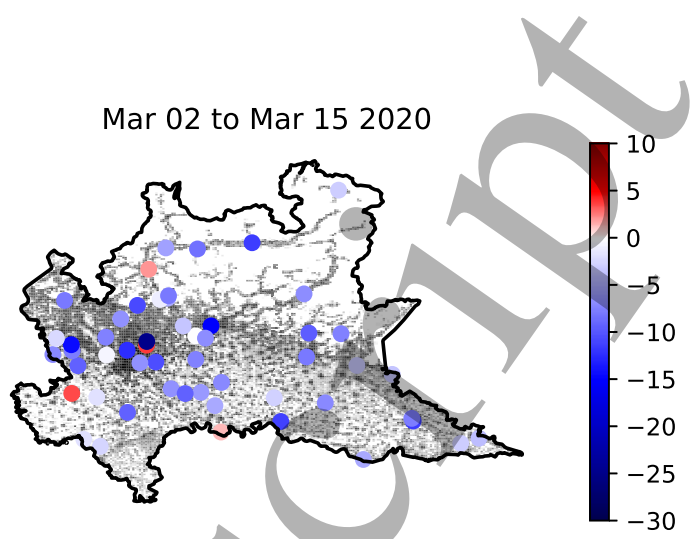

Mar 30 to Apr 122020

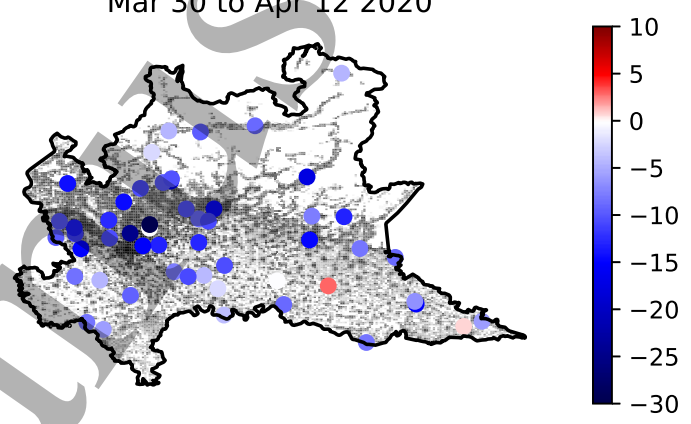

Apr 27 to May 032020

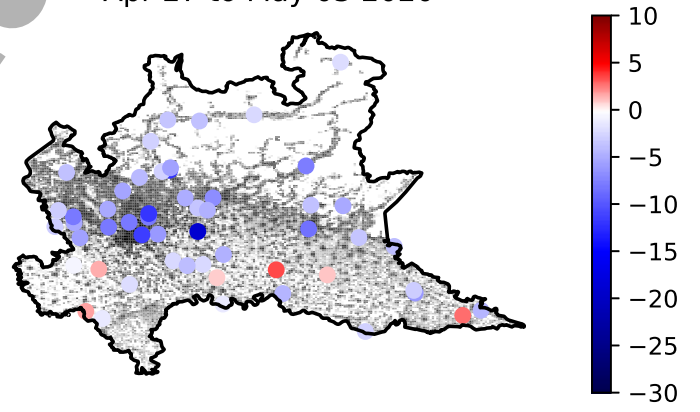

Figure A.14: Estimated reductions in concentrations of $\mathrm{NO}_{2}$ in $\mu \mathrm{g} / \mathrm{m}^{3}$ at background monitoring stations during the lockdown. Grey pixel are a $1 \mathrm{~km}$ by $1 \mathrm{~km}$ population grid. 


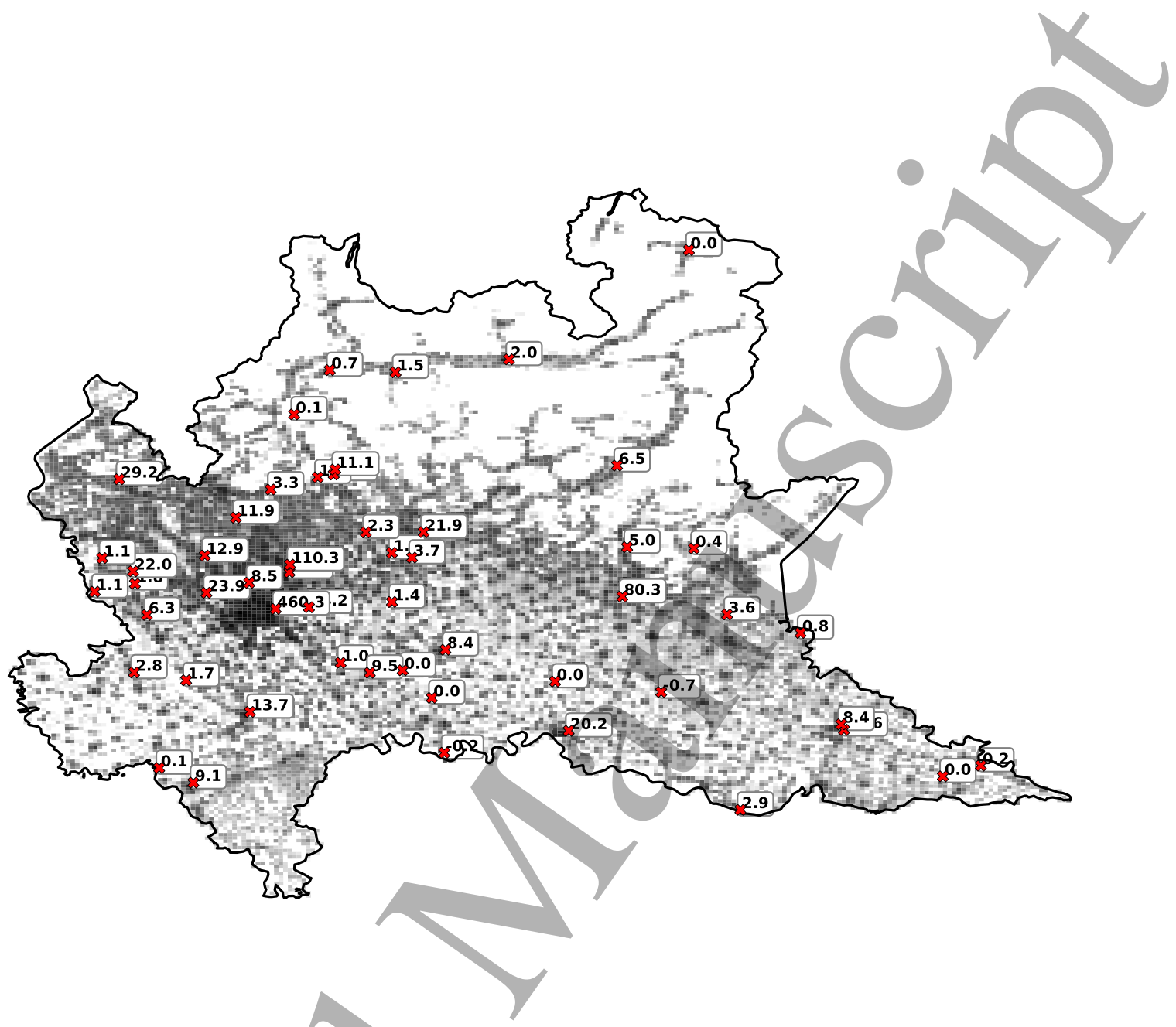

Figure A.15: Premature deaths avoided by reductions in $\mathrm{NO}_{2}$ within $20 \mathrm{~km}$ of background monitoring stations. Territory within less than 20 kilometers from two or more monitors is assigned to the closest one. 


\section{A.5 Lockdown of Lombardy}

Italy has witnessed one of the first major outbreak of COVID-19 outside China. The virus has first been identified in two Chinese tourists who had arrived at Milano Malpensa Airport and, on January 31st, tested positive for the virus when visiting Rome (ANSA 2020b). For the next three weeks, only a handful of cases had been identified and all had a direct link with known hot-spots, such as a student returning from vacation in Wuhan and a couple of tourists from Taiwan (ANSA 2020a,c).

However, on February 21st, the first non-imported cases and the first death related to COVID-19 in the country were confirmed in lower Lombardy. By the end of the day, 17 individuals had been tested positive, 15 of which in Lodi and surroundings, in lower Lombardia, and 2 in the neighboring region of Veneto. The largest hotspot had been identified in the hospital of Codogno, where 5 members of the medical staff and 3 patients had tested positive to COVID-19. On the same day, the Minister of Health announced severely restrictive measures on 11 municipalities and over 50000 people. Until further notice, schools and all public and sporting events were suspended; non-essential production, commercial activities and public offices had to close doors; self-isolation at home was mandated and enforced; access to the municipalities was monitored by police and armed forces (Presidente del Consiglio dei Ministri 2020c; ANSA 2020d; La Repubblica 2020; Guidelli 2020) Also, self-isolation for two weeks was mandatory for whoever in the country had had contacts with confirmed cases. Violations of lockdown areas and self-isolation could be sanctioned with fines and up to a three months prison sentence (Presidente della Repubblica 2020; Ministro della Salute 2020a).

Over the next two days, local goyernments all over the country imposed restrictions of heterogeneous degrees, with strictest measures in the regions of Lombardia and Veneto. In Lombardia, the regional government suspended all teaching activities in schools and universities, prohibited public events, and suspended religious gatherings; pubs had to close by 6 pm (Ministro della Salute 2020b).

Local measures were soon followed by the intervention of the central government. On February 25th, the Prime Minister signed a Law Degree to expand and incorporate containment efforts in hotspot regions of Northern Italy. The decree closed schools and universities (originally until March 15th) and recommended remote working in Emilia Romagna, Friuli 
Venezia Giulia, Lombardia, Veneto, Liguria, and Piemonte (Presidente del Consiglio dei Ministri 2020d).

A week later, on March 1st, the government extends previous measures and prescribes non-restrictive ones over non-affected regions(Presidente del Consiglio dei Ministri 2020b); on March 4th, it announces all schools and universities in the countries will close.

By March 7th, 5883 cases had been confirmed in Italy and 233 COVID-19-related deaths recorded (Protezione Civile 2020). Despite containment measures, the growing number of confirmed cases and deaths pressured the Italian government to impose stricter controls. With a Law Decree on March 8th, Italy became the first country in Europe to impose a lockdown over Lombardia and 14 provinces of the northern and central regions of Piemonte, Emilia-Romagna, Veneto, and Marche. The restrictive measures were soon extended to the rest of the country on the following day. The decree imposed compulsory social distancing and self-isolation at home and the halt of all non-essential economic activities (Presidente del Consiglio dei Ministri 2020a; Presidenza del Consiglio dẹi Ministri 2020).

The list of sectors and activities deemed essential had been furthered narrowed on March 23rd; most notably, construction works were stopped, and all public offices had to close (Presidente del Consiglio dei Ministri 2020e). The lockdown then continued under virtually unaltered conditions until May $3 \mathrm{rd}$.

\section{A.6 Averaging wind speed and diréction}

Consider two vectors $s^{\prime}=\left[s_{1}, \ldots, s_{h}, \ldots, s_{24}\right]$ and $d^{\prime}=\left[d_{1}, \ldots, d_{h}, \ldots, d_{24}\right]$ containing hourly data on wind speed and direction, respectively. Speed and direction at hour $h$ are $s_{h}$ and $d_{h}$. To calculate average wind speed and average wind direction we:

1. Convert wind direction from degrees to radians $r=d \cdot \pi / 180$

2. Calculate the average of East-West and North-South speed components and invert sign.

$\bar{s}^{E W}=-\frac{1}{24} \sum s_{i} \cdot \sin \left(r_{i}\right)$

$\bar{s}^{N S}=-\frac{1}{24} \sum s_{i} \cdot \cos \left(r_{i}\right)$

3. Calculate average wind speed $S=\sqrt{\bar{s}^{E W^{2}}+\bar{s}^{E W^{2}}}$ 
4. Calculate average wind direction $\bar{r}=\arctan 2\left(\bar{s}^{N S}, \bar{s}^{E W}\right)$

5. Convert radians to degrees $\bar{d}=\bar{r} \cdot 180 / \pi$

$$
D= \begin{cases}\bar{d}+180 & \text { if } \bar{d}<180 \\ \bar{d} & \text { if } \bar{d}=0 \\ \bar{d}-180 & \text { if } \bar{d}>180\end{cases}
$$

$D$ is the average wind direction, and $S$ is the average wind spéed.

\section{A.7 Effects on economic activity and morbidity}

We report here an estimate of the theoretical gains in GDP and lost workdays from air pollution-related illness due to the improvement in air quality, but absent the pandemic.

To calculate the aggregated productivity gains, we employ the results of Dechezleprêtre et al. (2019), who use thermal inversions to identify the causal impact of air pollution on economic activity. They estimate that a one $\mu g / m^{3}$ increase in $\mathrm{PM}_{2.5}$ concentration leads to a $0.8 \%$ decrease in regional annual GDP. Accordingly, the average reduction of $\mathrm{PM}_{2.5}$ by $3.84 \mathrm{\mu g} / \mathrm{m}^{3}$ for two months corresponds, for simplicity ignoring the exponential growth process, to $3.84 \cdot 0.8 / 6=+0.512 \%$ in regional annual GDP.

We compute the number of lost workdays from air pollution-related illnesses as in Vandyck et al. (2018). They assume a fixed ratio of 547 avoided lost workdays per avoided premature mortality. The multiplier was derived from the WHO-HRAPIE recommendations, based on earlier work, and applied in the context of the EU Clean Air Package. Following this methodology, we calculate that 5579.4 to 13565.8 lost workdays have been avoided by reducing $\mathrm{PM}_{2.5}$ concentrations; and 15753.6 by the decrease in $\mathrm{NO}_{2}$ concentrations. 